University of Louisville

ThinkIR: The University of Louisville's Institutional Repository

Electronic Theses and Dissertations

8-2017

\title{
Biomechanical testing of an exercise for strengthening the proximal femur.
}

Alyssa Osbourne

University of Louisville

Follow this and additional works at: https://ir.library.louisville.edu/etd

Part of the Biomechanical Engineering Commons, Biomechanics and Biotransport Commons, Biomedical Devices and Instrumentation Commons, Musculoskeletal System Commons, Orthopedics Commons, Sports Medicine Commons, and the Therapeutics Commons

\section{Recommended Citation}

Osbourne, Alyssa, "Biomechanical testing of an exercise for strengthening the proximal femur." (2017). Electronic Theses and Dissertations. Paper 2813.

https://doi.org/10.18297/etd/2813

This Master's Thesis is brought to you for free and open access by ThinkIR: The University of Louisville's Institutional Repository. It has been accepted for inclusion in Electronic Theses and Dissertations by an authorized administrator of ThinkIR: The University of Louisville's Institutional Repository. This title appears here courtesy of the author, who has retained all other copyrights. For more information, please contact thinkir@louisville.edu. 


\title{
BIOMECHANICAL TESTING OF AN EXERCISE FOR STRENGTHENING THE PROXIMAL FEMUR
}

\author{
By \\ Alyssa Osbourne \\ Bioengineering B.S., University of Louisville, 2015
}

\author{
A Thesis \\ Submitted by the faculty of the \\ University of Louisville \\ J.B. Speed School of Engineering \\ as Partial Fulfillment of the Requirements \\ for the Professional Degree
}

MASTER OF ENGINEERING

Department of Bioengineering

June 2017 


\section{BIOMECHANICAL TESTING OF AN EXERCISE FOR STRENGTHENING THE PROXIMAL FEMUR}

Submitted by: $\frac{\text { A. Qbbowme }}{\text { Alyssa Osbourne }}$

A Thesis Approved On:

$\frac{6-29-2017}{\text { Date }}$

By the Following Reading and Examination Committee:

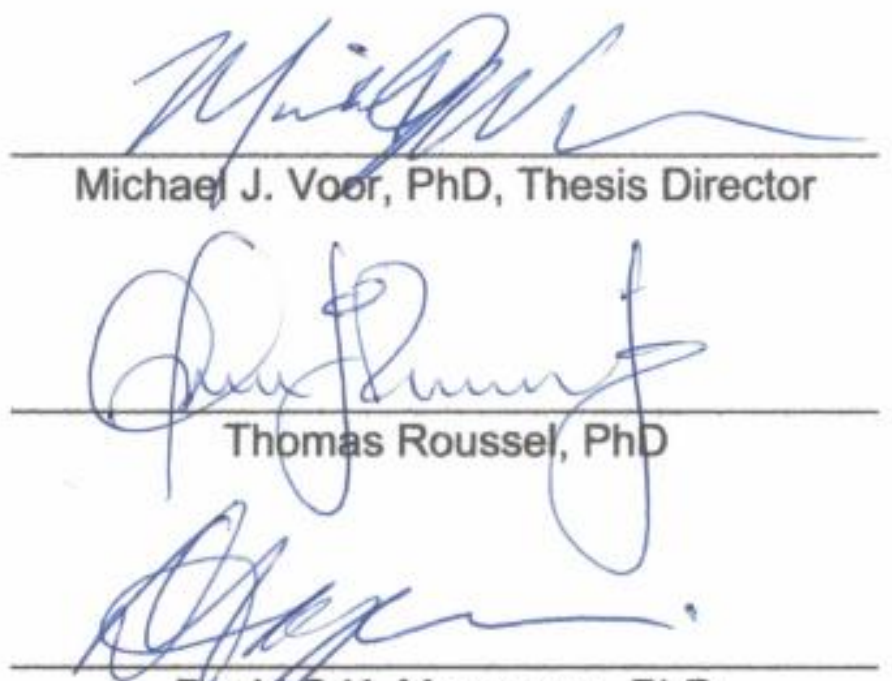

Dayió S.K. Magnuson, PhD 


\section{ACKNOWLEDGEMENTS}

First, I would like to thank Dr. Michael J. Voor, for his knowledge, mentorship and the opportunity to work on this exciting and rewarding project. I would also like to thank Dr. David S.K. Magnuson and Dr. Thomas Roussel for the support and willingness to serve on my committee.

Additionally, l'd like to acknowledge Kaitlyn Rapson for her work on the original prototype of the exercise device. Furthermore, l'd like to recognize Dr. Kibbe and Nicholas Link for their help in the cadaver experiments.

This research would not be complete without the combined efforts of all these people and for that, I am genuinely grateful. 


\begin{abstract}
Hip fractures are one of the most prevalent fragility injuries occurring over 258,000 times per year in the U.S. alone and resulting in not only a huge social and economic burden but also a resounding increase in the mortality rate among the injured individuals. These hip fractures most commonly result from a fall to the side impacting the greater trochanter and propagating a fracture across the femoral neck. Low bone density in the form of osteopenia or osteoporosis increases the risk of these fractures.

Current treatment options for low bone density are least effective at strengthening the hip compared to other sites in risk of fracture. So, based on the principles of cutting edge bone remodeling research, a unique therapeutic exercise device was designed specifically to improve bone quality at the most critical location prone to fracture: the superior-lateral femoral neck where the fracture first initiates during a fall. The exercise involves dynamically abducting the user's legs into the pads of the device positioned proximally on the outer thigh. The exercise/device is intended to work by inducing enough strain on the bone to stimulate the body's natural bone remodeling mechanisms to increase bone density in the proximal femur and consequently prevent a fracture from arising if a fall to the side does occur.
\end{abstract}


In order to test the proposed exercise, experiments simulating the exercise were completed using a prototype device and (1) an artificial composite femur, (2) an ex-vivo cadaveric femur and (3) in-situ in a cadaver. Strains were measured at three critical locations on the femurs, including the lateral neck, medial neck and medial shaft. Additionally, a computer model representing a femur and the applied loading conditions of the exercise was developed and a finite element analysis (FEA) was performed. The results of the FEA were compared to the experimental results and used to optimize the exercise and test its safety and effectiveness.

During the in-situ cadaver experiment, the strain magnitudes measured in the femoral lateral neck reached 1511.3 microstrain $(\mu \varepsilon)$ in compression, with a strain rate of $36,954 \mu \varepsilon / s(S D=8,933)$. The FEA confirmed these strain values and revealed at an optimal pad position, peak strains were $2467.3 \mu \varepsilon$ (tension) in

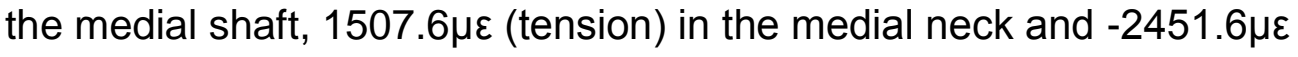
(compression) in the lateral neck.

When compared to published bone mechanical stimulation research, these results suggest that the proposed exercise has the potential to produce high enough strain magnitudes $(>1,000 \mu \varepsilon)$ and strain rates $(>10,000 \mu \varepsilon / s)$ in the critical location of the superior-lateral femoral neck in order to induce anabolic bone remodeling, while being well below the fracture limit in any area of the femur. This suggests that the proposed exercise could be a beneficial therapy for strengthening the proximal femur and may aid in the prevention of hip fractures. 
TABLE OF CONTENTS

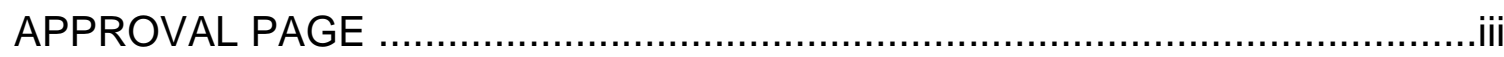

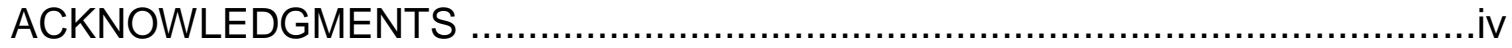

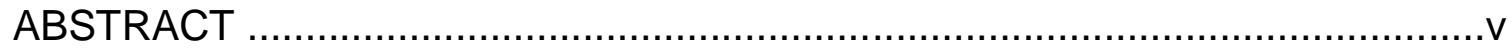

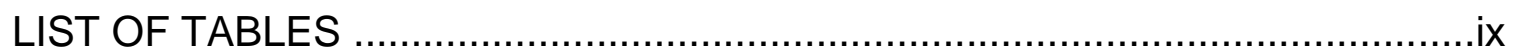

LIST OF FIGURES

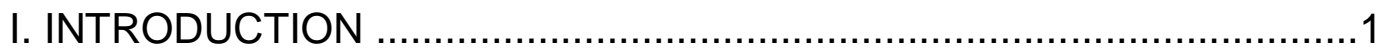

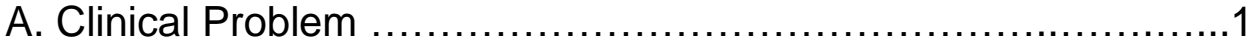

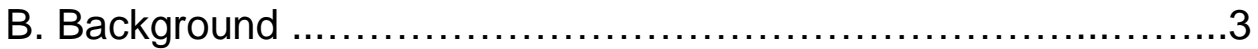

1. Bone Remodeling .....................................

2. Mechanical Stimulations \& Animal Literature ..............5

3. Exercise Literature .................................... 7

4. Biomechanics of Hip Fractures ........................

C. Proposed Solution / Research ................................11

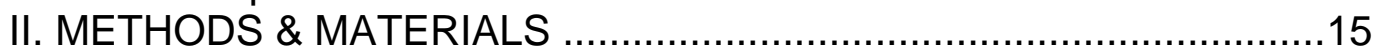

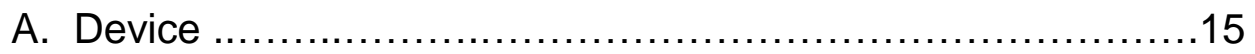

B. Device Sensor Calibration ...................................16

C. Realistic Human Capability ...................................17

1. Force Determination ..................................17

2. Kinematic Information ..............................18

D. Artificial Sawbone Experiment ................................19

E. Ex-vivo Cadaveric Femur Experiment …...................22

F. In-situ Cadaver Experiment .................................22

G. In-silico Computational Solidworks Model .......................24

1. Model \& Finite Element Analysis ....................24

2. Sawbone FEA .....................................28

3. Cadaveric Femur FEA .............................28

4. Cadaver FEA ......................................29

5. Optimization .......................................29

6. Proof of Concept: Safety \& Effectiveness .............30

III. RESULTS ......................................................... 31

A. Artificial Sawbone Data ....................................31

B. Ex-vivo Cadaveric Femur Data ...............................34

C. In-Situ Cadaver Data ...........................................

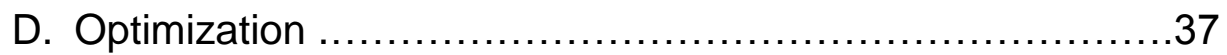

E. Proof of Concept: Safety \& Effectiveness .................... 38

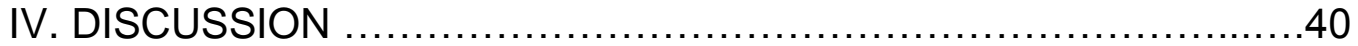

A. Limitations .............................................. 40

B. Considerations \& Future Development .......................41

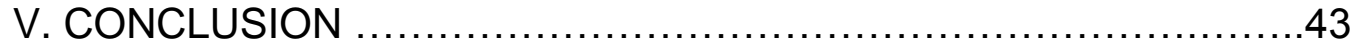

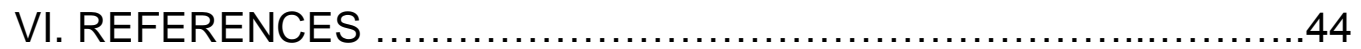

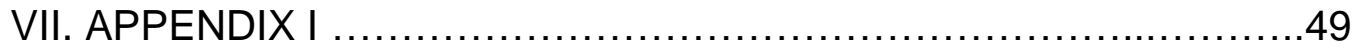


VIII. APPENDIX II

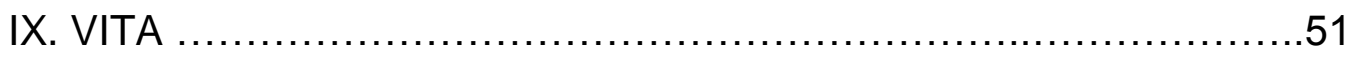




\section{LIST OF TABLES}

TABLE I - STRAIN GAUGE SPECIFICATIONS ..............................16

TABLE II - SAWBONE MATERIAL PROPERTIES ............................28

TABLE III - POOR QUALITY BONE MATERIAL PROPERTIES .................28

TABLE IV - STRAIN RESULTS AT DIFFERENT PAD PLACEMENTS .............38

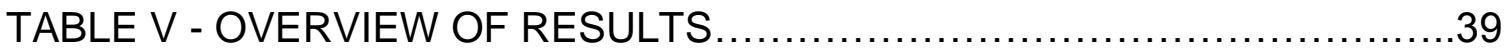




\section{LIST OF FIGURES}

FIGURE 1 - Schematic comparing healthy bone to osteoporotic bone in the proximal femur (A.D.A.M. Health Solutions). ................................

FIGURE 2 - Sketch representing the lower hindlimb of a mouse positioned for invivo mechanical loading using three-point bending. Downward movement of the loading point produces tibial bending with tension on the medial surface (Silva \& Brodt, 2008).

FIGURE 3 - Plain X-ray of a hip fracture (Dierselhuis, 2010).

FIGURE 4 - Stress distribution and magnitude in the femoral neck during (a) walking and (b) a fall to the side (Bakker, 2009).

FIGURE 5 - (a) A representative cross section of the adapted femoral neck of an older individual; showing a thinner superior cortex as compared to a thicker inferior cortex. (b) Location of cross section in 'a' (Bakker, 2009).

FIGURE 6 - Demonstration of the body position and movement of the proposed exercise using a prototype device.

FIGURE 7 - Abduction of the legs causes an inertial force at the knees, which when impacting a pad on the outer thigh, is balanced by reaction forces at the pad and hip. This creates compressive strains on the lateral side of the femur and tensile strains on the medial side of the femur.

Figure 8 - Strain gauges were mounted on the top and bottom of the lap bar, as indicated by the red arrows.

FIGURE 9 - Calibration curve developed for the exercise device. Variables include the applied force of the MTS machine vs. the voltage read by the strain gauges on the device.

FIGURE 10 - Sequential MaxTraq images of the exercise being performed tracing the angle of the legs during abduction in order to calculate the angular velocity.

FIGURE 11 - Strain gauge placement was based off of the work of Zani et al. (2015). Three critical locations were chosen as Lateral Neck (LN), Medial Neck $(\mathrm{MN})$ and Medial Shaft (M3). These placements were determined based on the Head Diameter (HD), and Biomechanical Length (BL). 
FIGURE 12 - Set of the sawbone experimentation, including (a) an artificial hip, (b) an instrumented sawbone positioned into the artificial hip and (c) overall setup for simulating the exercise.

FIGURE 13 - Placement of three strain gauges M3, MN, and LN on the explanted cadaver femur. .22

FIGURE 14 - The in-situ cadaver experimental setup.

FIGURE 15 - Alterations made to the model include (a) making a portion of the femoral head spherical and (b) adding a corresponding spherical acetabulum..24

FIGURE 16 - The design of the two part pad including a representation of the soft tissue $(A)$ and the pad $(B)$. 25

FIGURE 17 - Boundary condition of the FEA model: (a) the outer surface of the acetabulum fixed in space, (b) the back surface of pad fixed in space, (c) the lateral faces of the condyles restricted to movement normal to the top plane only. Also, the externally applied forces including (d) the initial angular velocity applied to the entire femur in rotation around Axis 1 .

FIGURE 18 - Mesh results of the FEA model.

FIGURE 19 - Location of three sensors M3, MN and LN in the FEA model that correspond to the experimental strain gauge placement.

Figure 20 - Pad placement at a) $80 \mathrm{~mm}$, b) $100 \mathrm{~mm}$ and c) $120 \mathrm{~mm}$ below the top of the greater trochanter.

FIGURE 21 - Strain gauge results for the artificial sawbone experiment, including ten different impacts of the pad (impacts ranging from 350-550N of applied force) for all three strain gauges M3, MN and LN.

FIGURE 22 - Anterior (left) and posterior (right) view of the artificial sawbone FEA results of (a) $3^{\text {rd }}$ principal compressive strains and (b) $1^{\text {st }}$ principal tensile strains.

FIGURE 23 - FEA compressive strain results showing the peak strain location in the lateral neck is not within the gauge / sensor location.

FIGURE 24 - FEA tensile strain results for a) the peak medial neck and shaft strains, b) anterior view and c) posterior view of the femur.

FIGURE 25 - FEA compressive strain results for a) the peak lateral neck strains,

b) anterior view and c) posterior view of the femur. 


\section{INTRODUCTION}

\section{A. Clinical problem}

Hip fractures are one of the most common traumatic fractures and yet can have some of the most prevalent and devastating consequences. Unfortunately, as the elderly population is rising we expect to see this problem grow with time. In 2010 , over 258,000 people age 65 years and older were hospitalized for hip fractures in the United States and the amount is expected to rise $11.9 \%$ by 2030 (Stevens \& Rudd, 2013). Not only are hip fractures one of the most prevalent fractures but they are also the most expensive fracture, costing the U.S. population $\$ 12.2$ billion in 2005 (Burge et al., 2007).

However, beyond its prevalence and economic impacts, probably the most alarming implication of hip fractures is the resultant increased mortality rate. In the year following hip fracture, patients are more than four times more likely to die than aged matched controls (Farahmand et al., 2005). For women the one year mortality rate has been shown to be $21.9 \%-29.0 \%$ and in men $32.5 \%-40 \%$ (Brauers et al., 2009, Huntjens et al., 2010), and in general the probability of death can be even higher within the first few months following fracture 
(Farahmand et al., 2005). Since "hip fracture" is not listed as the primary cause of these deaths and instead due to secondary consequences of the fracture, it is not rated as one of the top ten cause of death in the United States. However, the number of deaths that result from these fractures are comparable to death rates of diabetes (the $7^{\text {th }}$ leading cause of death), and higher than the death rates of influenza and pneumonia (the $8^{\text {th }}$ leading cause of death) (Heron, 2016). This is an astoundingly high number of deaths resulting from something that may be, to some extent, preventable.

Bone quality is a very important risk factor in hip fractures. Older adults with poor bone quality have a significantly increased chance for these types of fragility fractures (Kanis et al., 2008).
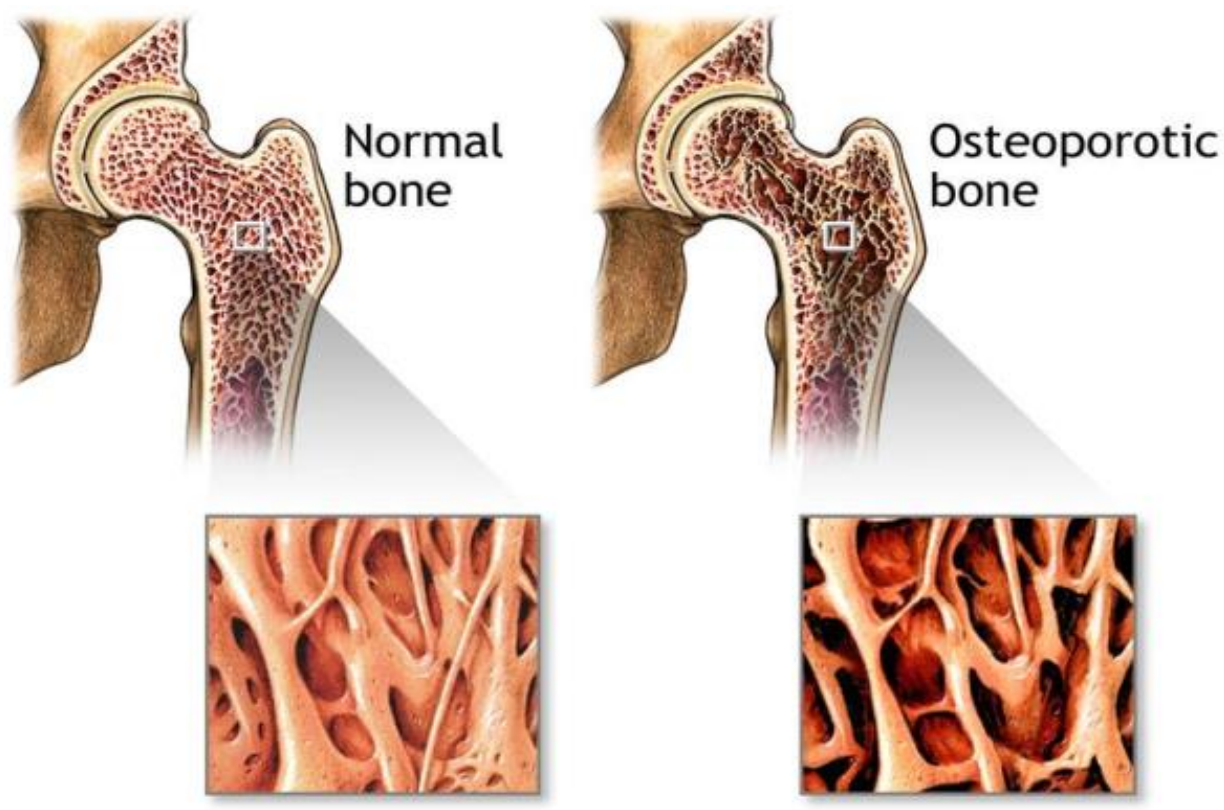

FIGURE 1 - Schematic comparing healthy bone to osteoporotic bone in the proximal femur (A.D.A.M. Health Solutions). 
Poor bone quality is also very common in elderly people, which makes this population more susceptible to hip fractures. Not only can the natural aging process lower bone mineral density (BMD), but with the addition of bone diseases such as Osteoporosis, the bone quality and strength is reduced even more and as a result the bones can become weak and fragile.

In 2016, the National Osteoporosis Foundation estimated that 54 million Americans have low bone density, with over 12 million having severely poor bone quality (osteoporosis) and the remaining 44 million with poor bone quality (osteopenia). That is nearly half of the US population ages 65 and older that have low bone density. Additionally, the lumbar spine and proximal femur are common areas prone to bone loss and therefore more vulnerable to fracture (Figure 1).

\section{B. Background}

\section{Bone Remodeling}

The human body is constantly undergoing the process of bone remodeling. It is known that about $10 \%$ of the skeleton is remodeled each year. In healthy remodeling there is a particular balance that is maintained between bone reabsorption and bone formation. This metabolism is closely monitored by the body in order to keep appropriate growth rates and differentiation. Unfortunately, this critical balance is hindered with age and osteoporosis, where the reabsorption rate can surpass the rate of formation and consequently make the bones brittle and weak (Narra, 2013). 
However, our skeleton doesn't only just remodel to repair and grow, but it's also mechanically sensitive to the loads we apply to it. Bone cells are "smart" in the way that they strengthen the bones where we need them to be strong in order to prevent fracture or damage when we preform the tasks of our everyday life. For this reason, bone adapts to habitual loading and can change depending on its environment. This intrinsic ability helps develop and remodel the skeleton according to its functional demands (Wolff, 1892).

The Mechanostat Theory dives into the specifics of this mechanically sensitive remodeling process and describes that the response is actually due to local elastic deformations of bone cells (i.e. strain). When bone experiences an externally applied force, strains are sensed by the mechanosensitive cells and if the strain magnitudes are high enough it can elicit remodeling. Specifically, bone that is exposed to less than $100 \mu \varepsilon$ is associated with disuse and bone is resorbed and loses mass. Whereas, strains applied within the adaptive window of $100-1000 \mu \varepsilon$ elicits homeostatic remodeling where bone mass is maintained (remodeling may occur but with no net gain or loss). Strains applied consistently with magnitudes of over $1000 \mu \varepsilon$ (particularly within 1000-1500 $\mu \varepsilon$ window) stimulate bone growth and therefore increase bone mass and bone strength. Yet, loads above $3100 \mu \varepsilon$ can begin to form microdamage and remodeling changes from lamellar bone formation to woven bone formation. Fracture may occur at strains around $25,000 \mu \varepsilon$ depending on age and bone quality (Frost, 1987; Frost, 2003; Jee, 2009). 


\section{Mechanical Stimulation \& Animal Literature}

Alternatively, other studies using mechanical stimulations to promote anabolic bone remodeling have shown that strain magnitude is not the only important factor. Frequency and strain rate also have an important effect, as well as exposing the bone tissue to unfamiliar, maybe even non-physiological loading conditions. Two basic loading methodologies have been used to experimentally induce bone remodeling through mechanical stimulation: low amplitude - high frequency, and high amplitude - low frequency loading conditions.

\section{Low amplitude - High frequency:}

For example, extensive research by Rubin and colleagues (2002) show ultrasound treatment utilizing extremely low strain amplitudes $(<10 \mu \varepsilon)$ at very high frequencies $(30 \mathrm{~Hz})$, and high strain rates have been able to show a positive effect on bone healing and also has the ability to increase trabecular bone mass or prevent trabecular bone loss. Additionally, whole body vibrational therapies using high frequency $(>10 \mathrm{~Hz})$ and low strain amplitude $(0.5-100 \mu \varepsilon)$ stimulation have been studied; results indicate that high frequency signals of far less than five microstrain can promote bone formation (Judex \& Rubin, 2010).

High amplitude - Low frequency:

Contrasting research on mechanical stimulation of turkey ulnas using axial loads at low frequency $(2.5 \mathrm{~Hz})$ for 5000 cycles/day, at strain magnitudes of $1000 \mu \varepsilon$ and strain rates of $15,000 \mu \varepsilon / s$, results in increased intracortical turnover 
(Rubin et al., 1996). Similarly, Fritton and colleagues (2008) also demonstrates cancellous bone mass loss can be prevented by axial mechanical loading on mouse tibia at $4 \mathrm{~Hz}, 1200$ cycles/day at strains of $1200 \mu \varepsilon$. Research by Robling (2001) also shows that dynamically loading rat ulnas at $2 \mathrm{~Hz}$ for 1200 cycles/day at strain magnitudes of $3500 \mu \varepsilon$ triggers an adaptive response.

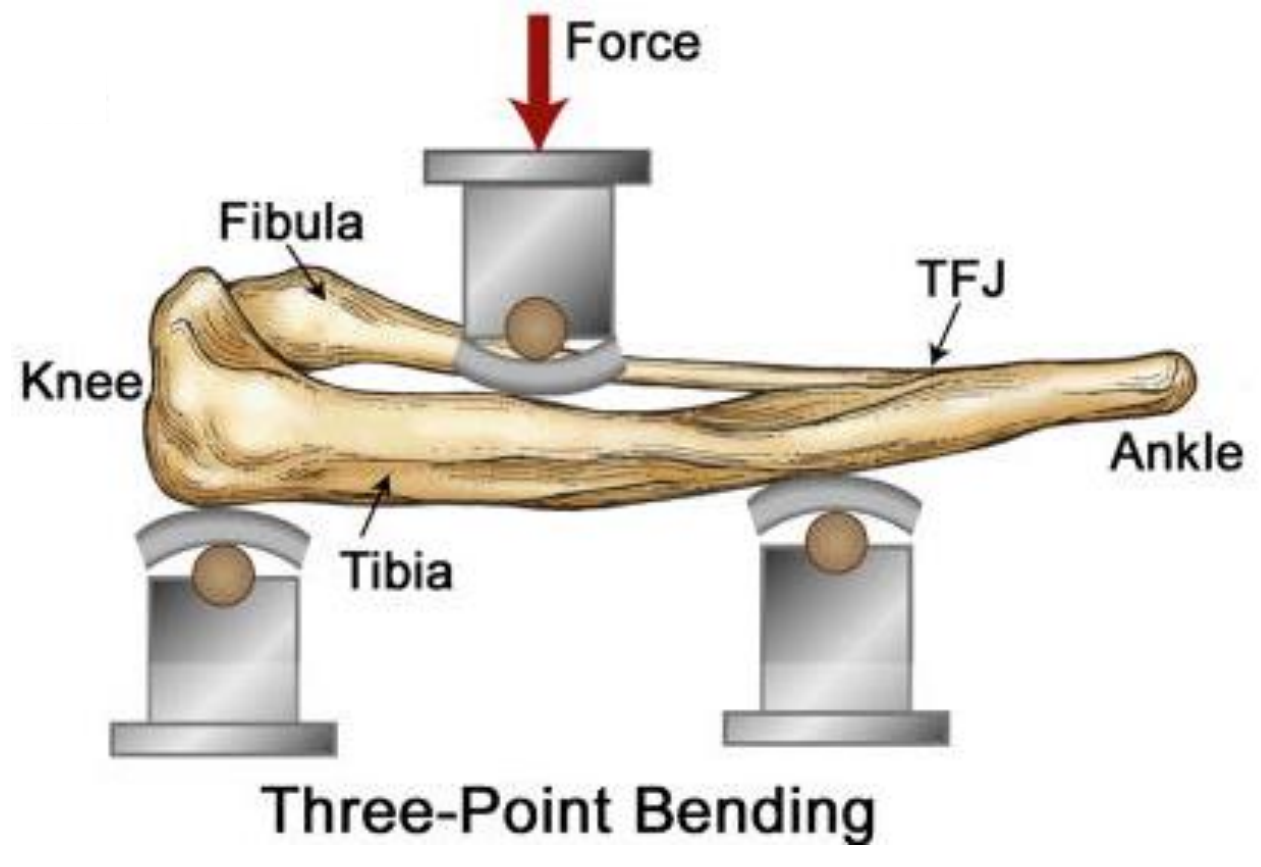

FIGURE 2 - Sketch representing the lower hindlimb of a mouse positioned for invivo mechanical loading using three-point bending. Downward movement of the loading point produces tibial bending with tension on the medial surface (Silva \& Brodt, 2008).

Furthermore, Brodt \& Silva (2010) showed by axially loading mouse tibias at strains of $900-3100 \mu \varepsilon$ with 10 second resting time in between each load for 60 cycles/day, results in a strong cortical response and increased cortical area in young and old mice. They also showed that 3-point bending (Figure 2) is a good tool that can be used to cause high strain magnitudes in the tibias and activate bone formation at the endocortex and periosteum. Results also showed that 
generally bone formation increased with increasing peak force (Silva \& Brodt, 2008).

All of this research demonstrates that strain rate may be just as important as strain magnitude and whether using mechanical stimulation of low amplitude (of only hundreds of microstrain) at high frequency or high amplitude (1000$3000 \mu \varepsilon)$ at low frequency, generally strain rates around the $10,000 \mu \varepsilon / \mathrm{s}$ range can evoke an anabolic cortical response.

\section{Exercise Literature}

In addition to using mechanical stimulation in animal models to study bone remodeling, research has also been conducted looking at the direct effects of human exercise and resistance training to the bone mineral density and cortical bone geometry in the femoral neck.

Kohrt et al. (1997) studied the effects of exercise training in BMD in older, sedentary women. It was discovered that exercises that introduced stress to the skeleton through ground-reaction forces (for example walking, jogging and stairs) had a larger effect on femoral neck BMD than joint-reaction force exercises (weight lifting and rowing).

Research done by Lang and colleagues (2014), found that resistance training in humans such as squats and deadlifts three times a week, for 16 weeks, increased vertebral and femoral neck cortical BMD, and standing hip abductions and adductions increased trochanteric cortical volume.

More recently, the osteogenic effects of recreational soccer and resistance training on elderly men has also been investigated. In 2014, Helge et al. found 
that four months of recreational soccer increased BMD in the proximal femur and the effects continued to develop even after 12 months.

This can also be seen in the work of Narra and colleagues in 2013. Narra categorized female athletes into groups depending on their typical training activity and compared them to age-matched controls. The groups included high impact (high and triple jump), odd impact (racket and soccer playing), high magnitude (power lifting), repetitive low impact (endurance running) and repetitive non-impact (swimming). Results suggested that the high impact group had weaker antero-superior regions of the femoral neck, but stronger inferior weight-bearing regions. This indicates that since the loading scenario was essentially a higher intensity of stance loading that the femoral neck only got stronger in the inferior regions where high compressive stresses were applied.

Narra (2013) also reported that the odd-impact group had stronger superior, posterior and anterior regions of the femoral neck. Signifying that oddimpact exercises that stress the femoral neck in varying directions in which it is unaccustomed, correlates with a stronger overall cross section of the femoral neck; this makes the proximal femur more resistant to loading conditions other than just normal gait.

What is common to all of these studies is that exercise can have an effect on BMD in the femoral neck and suggests that exercise can be used as a therapy to increase bone strength or prevent further bone loss. It is also obvious that the exercises that are more dynamic with high impact loading conditions seem to induce more osteogenesis, as compared to resistance training with more 
static, low impact loading conditions. However, the intensity of the exercise is not only important to encourage remodeling, but the direction of loading dictates where the bone remodeling occurs.

\section{Biomechanics of Hip Fractures}

Specifically a "hip fracture" is a fracture within the femoral neck or intertrochanteric region of the femur (Figure 3). A resounding $95 \%$ or more of hip fractures are caused by falls, most commonly falling to the side and impacting the greater trochanter (Parkkari et al., 1999; Hayes et al., 1993).

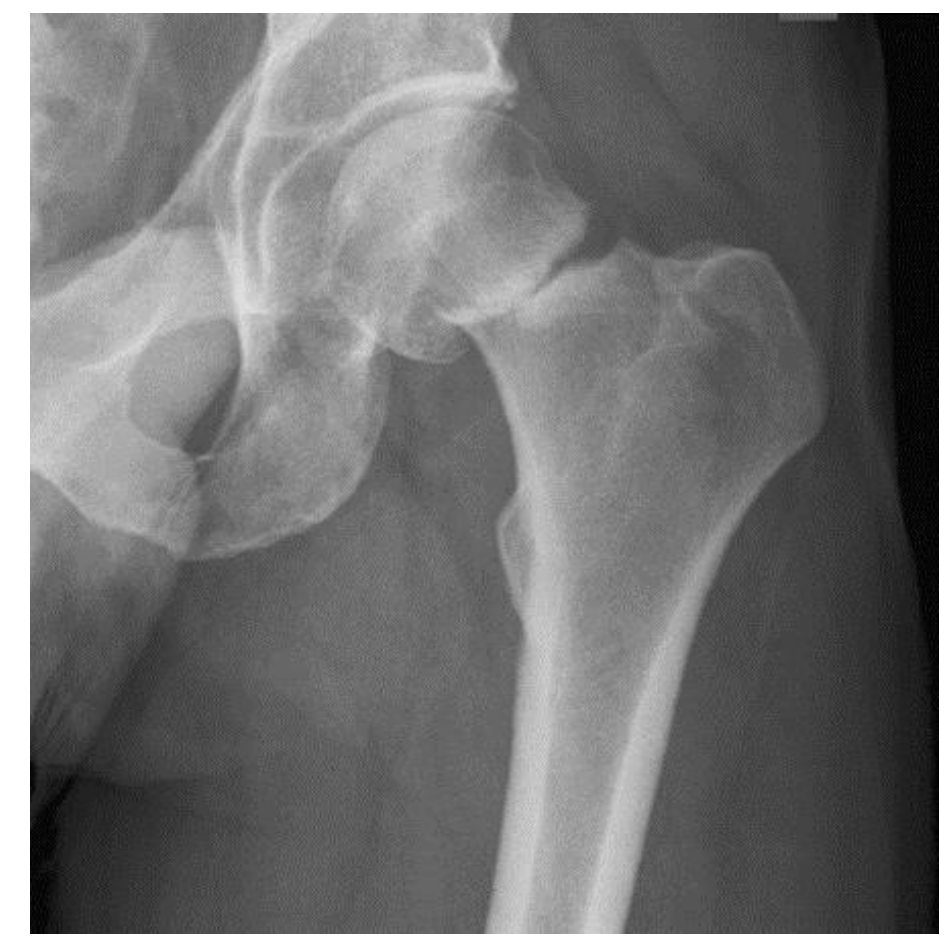

FIGURE 3 - Plain X-ray of a hip fracture (Dierselhuis, 2010).

Research has been performed on the mechanics and propagation of these fractures and how it relates to the bone geometry and remodeling tendencies (Bakker, 2009). During normal gait, maximum stresses occur in the neck region 
of the femur, with maximum compressive stress in the inferior region and tensile stress in the superior region (Figure 4).

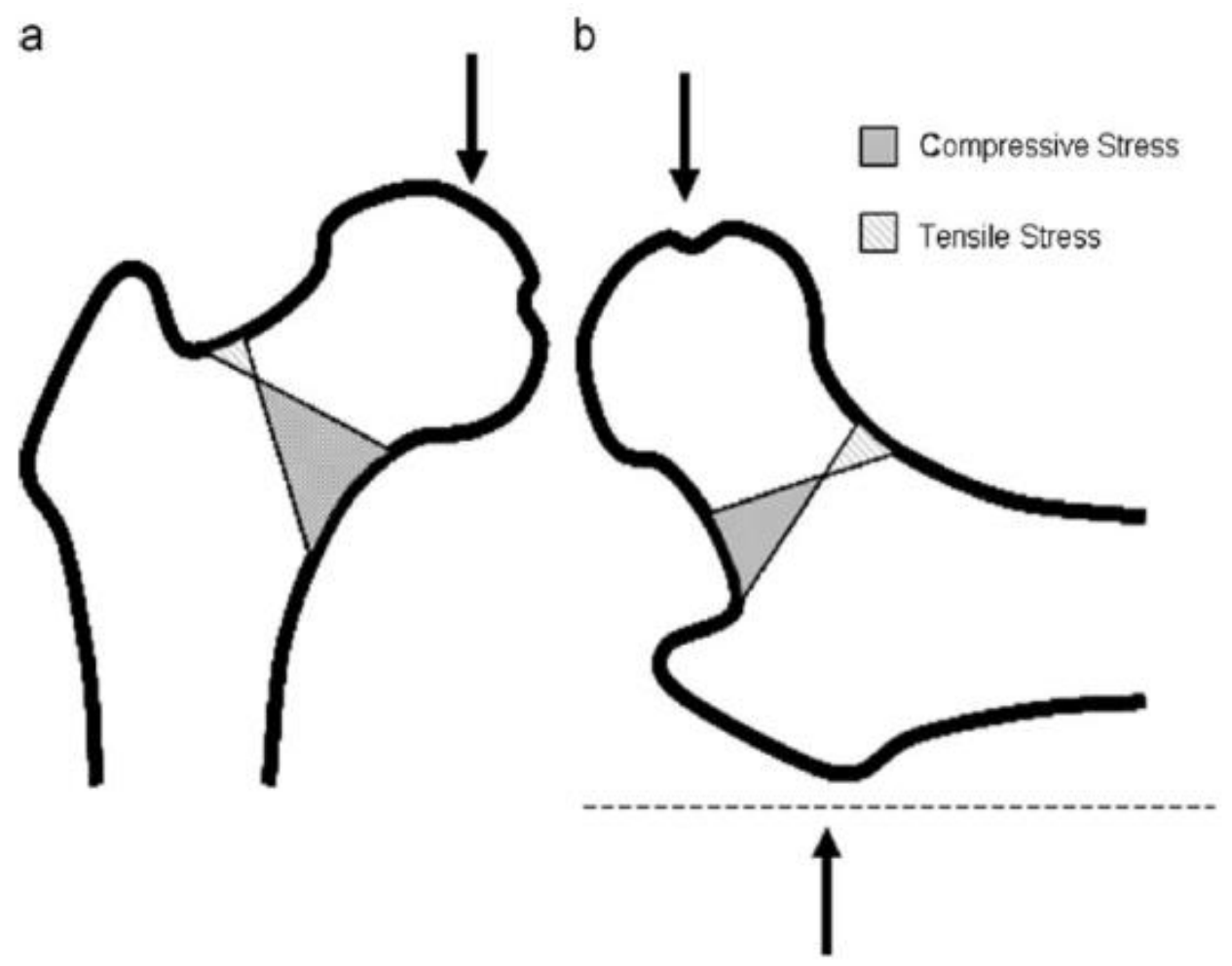

FIGURE 4 - Stress distribution and magnitude in the femoral neck during (a) walking and (b) a fall to the side (Bakker, 2009).

Therefore, over the course of a person's life, the femur is intended and remodeled for this loading condition. Consequently, in older individuals the superior cortex becomes considerably thinner than the inferior cortex, which is visible in the femoral neck cross section shown in Figure 5. For a fall to the side, these stress characteristics are reversed, with compressive stress in the superior region and tensile stresses in the inferior region (Figure 4) (Bakker, 2009; Yoshikawa, 1994). Since the femur is very rarely loaded in opposition, when a fall to the side does occur, the majority of the fractures involve a two-step failure process. The fracture initiates on the weak, thin superior neck first and then a 
second macroscopic crack develops in the inferior neck or medial intertrochanteric region (Bakker, 2009).
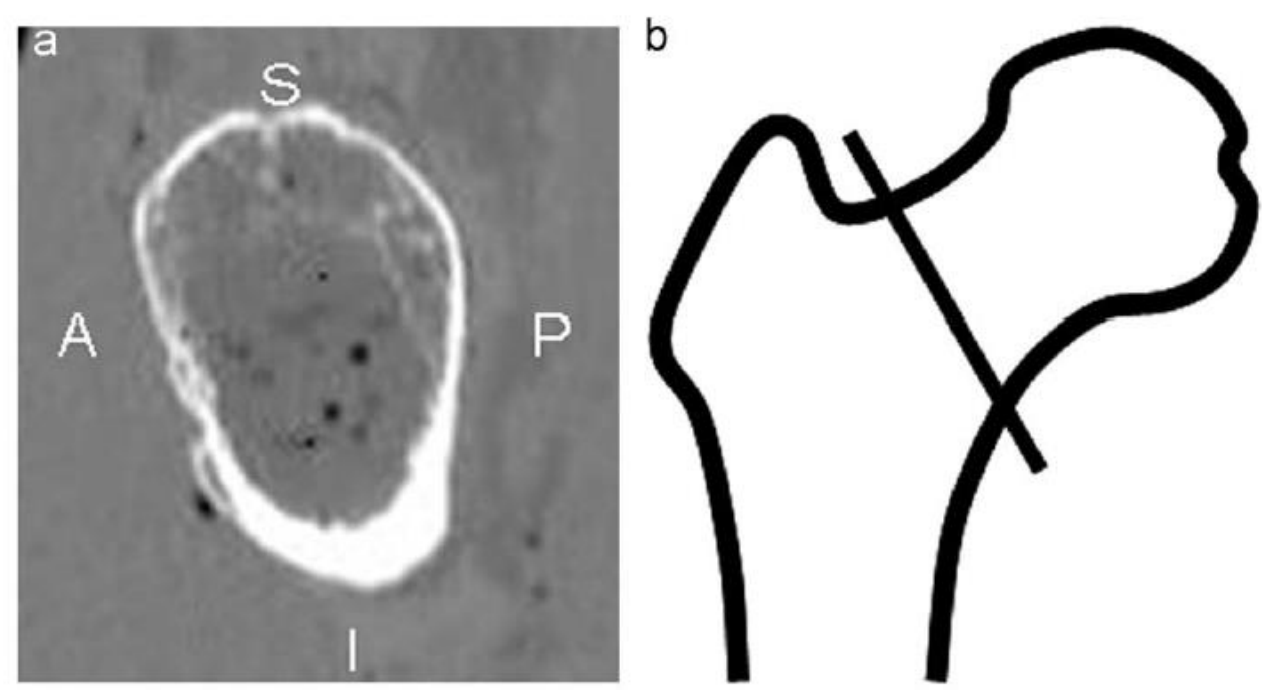

FIGURE 5 - (a) A representative cross section of the adapted femoral neck of an older individual; showing a thinner superior cortex as compared to a thicker inferior cortex (b) location of cross section in 'a' (Bakker, 2009).

Therefore, strengthening the supero-lateral neck in compression and the inferior-medial neck in tension is critical for preventing fracture.

\section{Proposed Solution / Research}

Most of the current solutions to femoral neck fractures involve drug therapy to increase overall bone density throughout the body or surgical intervention after a fall or fracture already occurs. However, the following thesis is a proposed solution for a preventative exercise therapy to strengthen the femur in the critical locations so that if a fall were to occur, then it would be less likely to result in fracture. As an additional supplementary benefit, exercising the lower body not only will strengthen the bone where it is needed but may also 
strengthen the abductor muscles that contribute to balance and strength in walking and standing, which may prevent a fall in the first place.

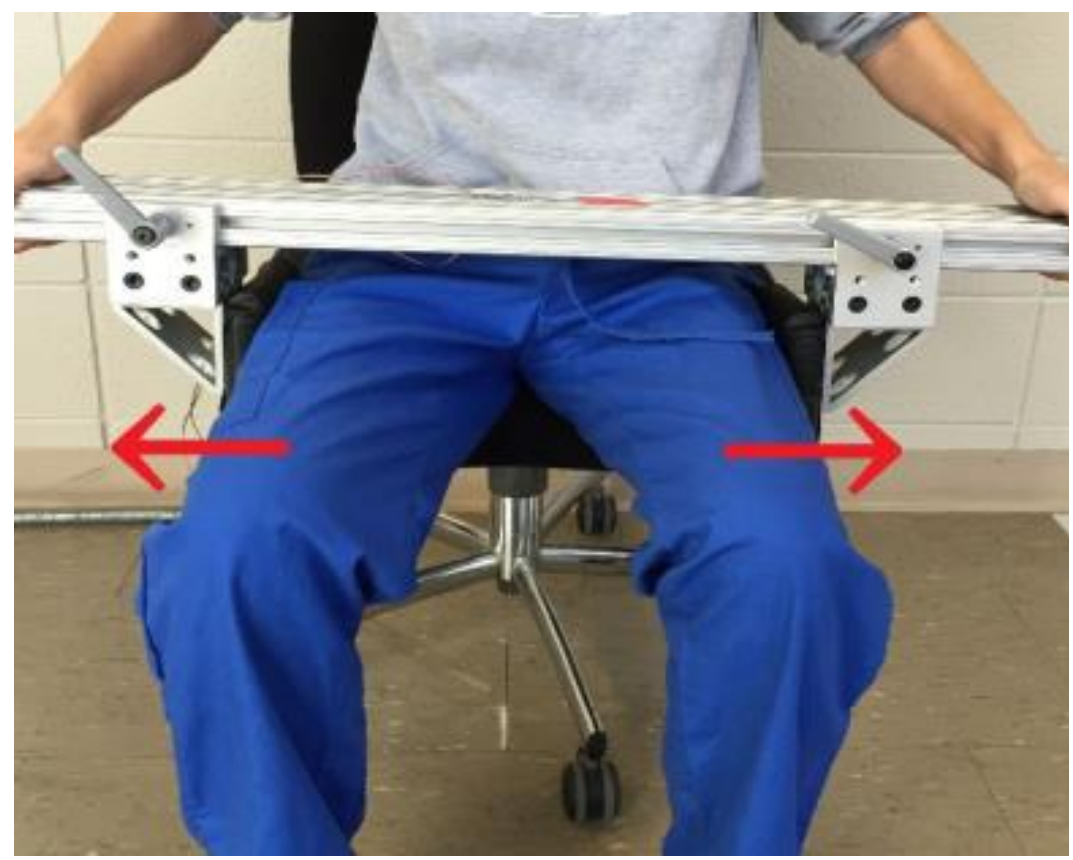

FIGURE 6 - Demonstration of the body position and movement of the proposed exercise using a prototype device.

The proposed exercise involves using an exercise device (Figure 6) for use at home or in a gym setting during a directed or self-monitored exercise program. It is designed for people entering the stages of poor bone health, including elderly individuals. In order to perform the exercise, the user should be in a sitting position (hips at 90 degrees), with the resistance pads positioned touching the proximal outer thigh at the location just below the lateral prominences of the greater trochanter. Knees should be flexed approximately 90 degrees with both feet on the floor spaced about shoulder width apart. Using quick, dynamic motions the user should abduct both legs simultaneously and forcibly push against the two resistance pads with the outer thighs and then return to the neutral starting position. 
The initial hypothesis is that the exercise protocol should include twenty repetitions of this action with a pause (>10 s) between each repetition. Three or four sets of 20 repetitions should be performed three to five days a week. This protocol is modeled after the loading regimen designed by Brodt \& Silva (2010) described in the previous section, which utilizes a triangle loading and unloading waveform with a 10-second rest period between each loading event.

The concept of using bending to promote cortical bone formation will also be employed: by moving the knee outward during the exercise, it creates a inertial force, which on impact of the outer thigh against the pad develops a $2^{\text {nd }}$ force which is driven though the femoral neck and is eventually resisted by a $3^{\text {rd }}$ reaction force at the joint (Figure 7).

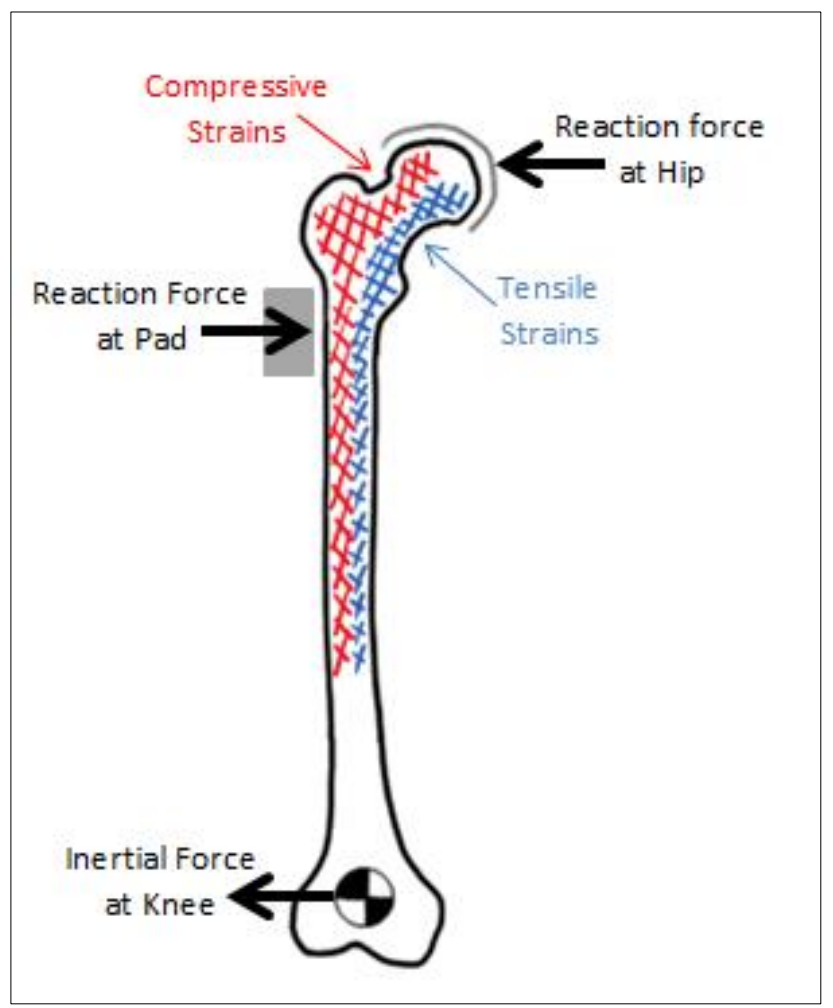

FIGURE 7 - Abduction of the legs causes an inertial force at the knees, which when impacting a pad on the outer thigh, is balanced by reaction forces at the pad and hip. This creates compressive strains on the lateral side of the femur and tensile strains on the medial side of the femur. 
Essentially the exercise exploits 3-point bending to replicate the loading conditions of a fall to the side at a lesser magnitude and higher frequency with the hope to induce the body's natural bone remodeling process in the critical regions prone to fracture.

The target population of this exercise would generally include anyone 45 and older who are either at risk of a hip fracture due to bone quality problems or have a close relative (such as a grandparent or parent) who has already experienced a hip fracture. More specifically, it would benefit the 44 million Americans that already have osteopenia or patients entering the osteoporotic stage of bone degradation. Additionally, it could be advantageous for anyone who is aware of the importance of good bone heath and desires to prevent a hip fracture from occurring.

Since there is no current way to non-invasively measure the strains in-vivo in the femur during the proposed exercise in human patients, a series of experimental tests using artificial bones as well as cadaver studies were performed. Subsequently, a Finite Element Analysis (FEA) computer model was designed and validated using the experimental data in order to optimize the exercise as well as prove its safety and effectiveness. 


\section{METHODS \& MATERIALS}

\section{A. Exercise Device}

The first generation prototype exercise device used in this research was fabricated prior to the experiments outlined in this thesis, using extruded aluminum and associated fasteners (80/20, Inc.). The basic structure shown in Figure 8 includes a lap bar and two vertical impact pads that are adjustable to the width of the patient's hips.

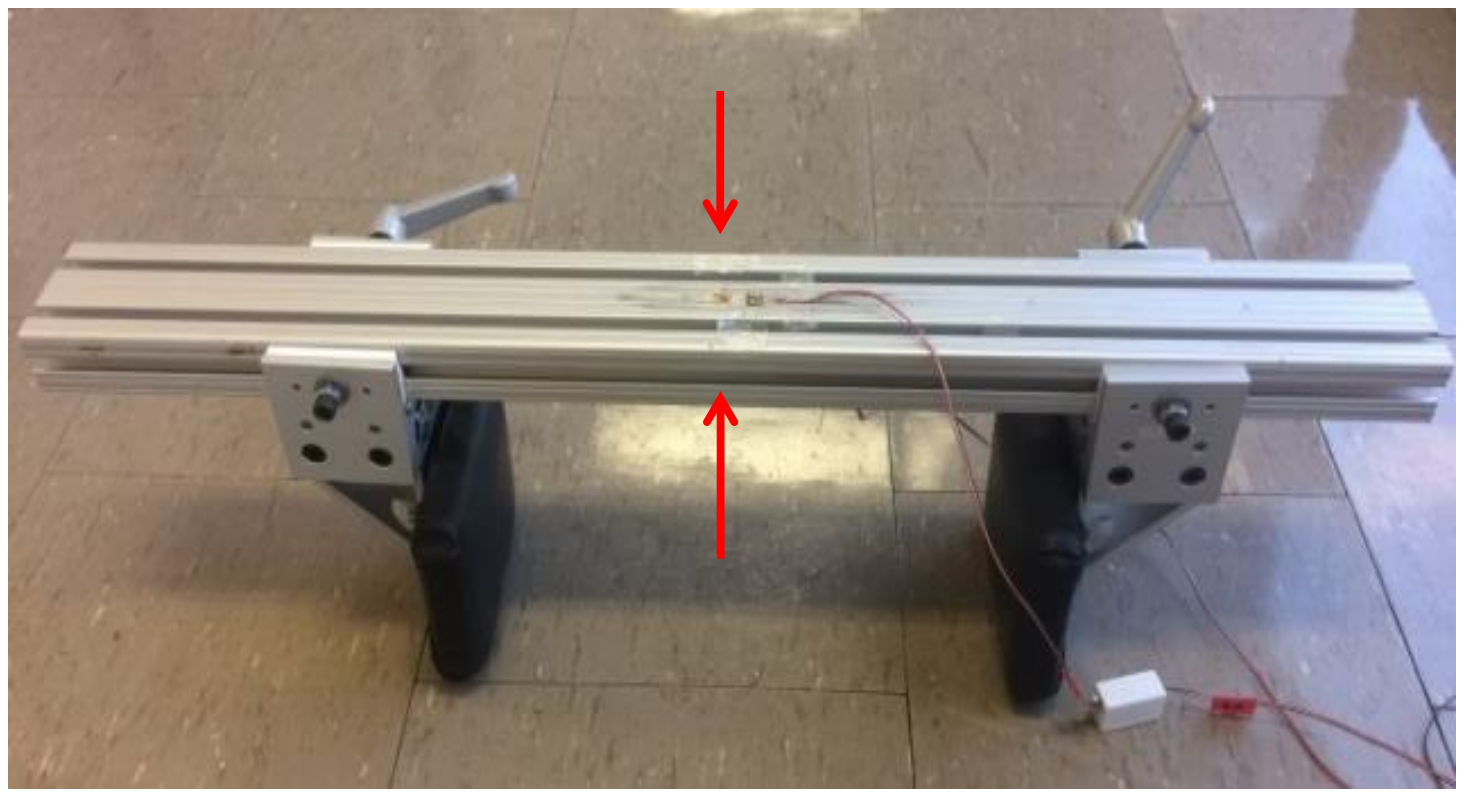

Figure 8 - Strain gauges were mounted on the top and bottom of the lap bar, as indicated by the red arrows. 


\section{B. Device Sensor Calibration}

Strain Gauges (specifications in Table I) were mounted (per the protocol in Appendix I) centered on the top and bottom of the lap bar of the device. These strain gauges were connected using a half bridge and then connected to the data acquisition system (DAQ) and LabVIEW program. Using a MTS machine the pads of the exercise device were slowly pushed outward at $1 \mathrm{~mm} / \mathrm{s}$ for total of $20 \mathrm{~mm}$. As the pads are pushed outward the lap bar bends, the deformation causes the electrical resistance of the strain gauges to change, which in turn changes the voltage measured across the gauges.

TABLE I

STRAIN GAUGE SPECIFICATIONS

\begin{tabular}{|c|c|}
\hline \multicolumn{2}{|c|}{ icro-Measurements Precision Sensors } \\
\hline Part \# & MMF019403 \\
\hline Grid Resistance (in Ohms): & $120.0+/-0.3 \%$ \\
\hline TC of gauge factor $\% 100^{\circ} \mathrm{C}:$ & $(+1.3+/-0.2)$ \\
\hline Gauge factor @ $24^{\circ} \mathrm{C}=$ & $2.110+/-0.5 \%$ \\
\hline Transverse Sensitivity: & $(+1.0+/-0.2 \%)$ \\
\hline
\end{tabular}

By recording the force measured by the MTS machine $(\mathrm{F})$ and bridge voltage measured across the strain gauges $(\mathrm{V})$, a correlation curve was created (Figure 9) so that the force being applied to the pads could be calculated from the strain gauges. Using this linear relationship the LabVIEW program was edited so that real time impact force measurements could be measured as the exercise was simulated.

$$
F=1.5978 V+1.4439
$$




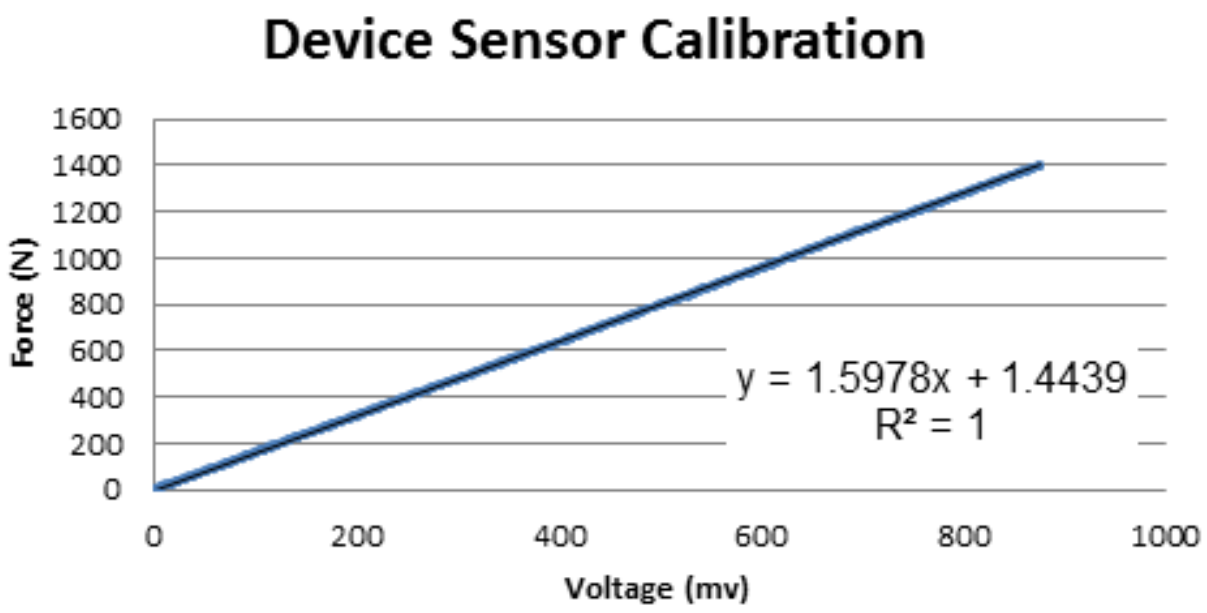

FIGURE 9 - Calibration curve developed for the exercise device. Variables include the applied force of the MTS machine vs. the voltage read by the strain gauges on the device.

\section{Realistic Human Capability}

\section{Force Determination}

In order to determine realistic forces applied to the pads of the device, data was collected from several students as they performed the proposed exercise. It was found that using the device with the pads positioned proximal on the femur, peak forces achievable ranged from 350.2-557.9 N, with an average of $445.9 \mathrm{~N}$. Since the nature of the exercise is very dynamic and the soft tissue of the upper thigh is striking the pads, the intensity in which the subjects hit the pad varied the comfort levels of the exercise. About $350 \mathrm{~N}$ was reported as soft impacts, $450 \mathrm{~N}$ hard but comfortable, and $550 \mathrm{~N}$ very hard and somewhat uncomfortable. Therefore, the goal of $450 \mathrm{~N}$ was chosen for the following experiments as an appropriate amount of force being applied to the pads. 


\section{Kinematic Information}

Since the force applied to the pads was measured through the bending of the material of the bar, it does not necessarily correlate perfectly to the actual reaction force at the pad. In this way, the "calibration" of the force at the pad from the experiments was inherently inaccurate. Instead it was used more for a guide on the intensity of the exercise. So with the purpose of determining more appropriate input variables for the FEA model, kinematic data was used to translate the realistic $450 \mathrm{~N}$ force, into the angular velocity of the femur. To do this, a high speed camera was set up directly above a student as they performed the exercise. Reflective tracking dots were placed on both knees. Video was recorded at 200 frames/second and then uploaded into MaxTraq (Figure 10).

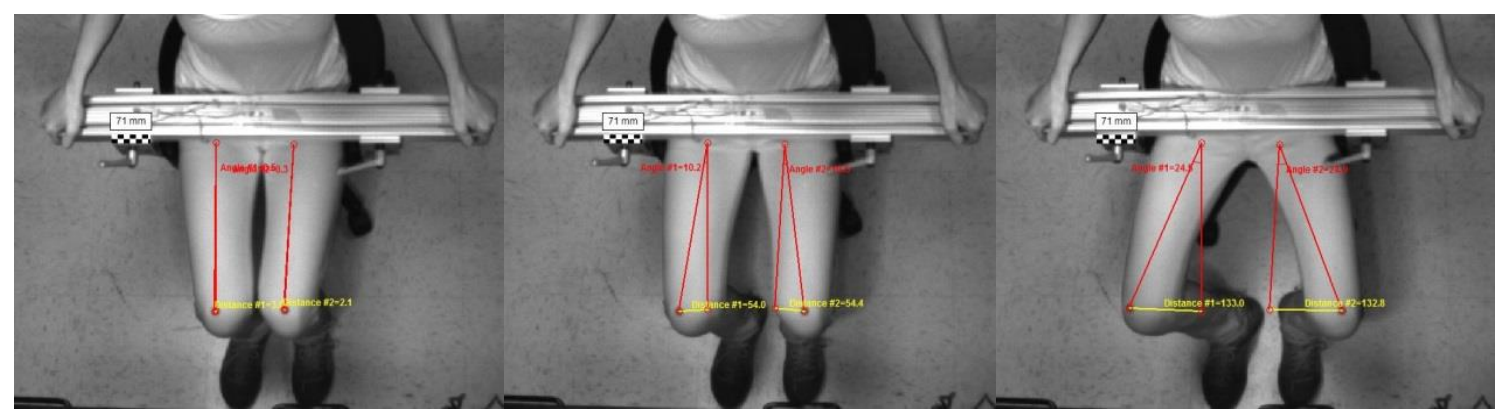

FIGURE 10 - Sequential MaxTraq images of the exercise being performed tracing the angle of the legs during abduction in order to calculate the angular velocity.

A stationary point was selected at the approximate position of both femoral heads and the position of each knee was traced as the legs moved throughout the exercise. Using the neutral starting position of the legs, the angular velocity was calculated throughout each abduction (see Figure 10). Just like the forces applied to the pads, the velocities also varied depending on intensity. It was calculated that the impacts ranged from $3.2 \mathrm{rad} / \mathrm{s}$ for soft impacts to $5.8 \mathrm{rad} / \mathrm{s}$ for 
very hard and somewhat uncomfortable impacts, with an average of $4.7 \mathrm{rad} / \mathrm{s}$ for hard but comfortable impacts.

Therefore, a secondary correlation was developed relating experimental force (F) applied to the pad, to angular velocity $(\omega)$ of leg during exercise:

$$
F=78.66 \omega+91.45, R^{2}=0.98
$$

\section{Artificial Femur Experiment}

In order to observe the strain distribution throughout the femur during the exercise, a simulation of the exercise was conducted using an artificial femur (specifically a $4^{\text {th }}$ generation Sawbone ${ }^{\mathrm{TM}}$ composite femur, Pacific Research Laboratories, Vashon Island, WA) and an artificial hip joint. This sawbone models cortical bone using a mixture of short glass fibers and epoxy resin around a foam core and is designed to be an artificial representation of an anatomical bone and have similar tensile and compressive strengths. First, the composite femur was instrumented with three strain gauges. Placement of these strain gauges was near the critical locations of the lateral neck (LN), medial neck (MN) and medial shaft (M3). Exact placements were determined using the procedure developed by Zani et al. (2015), seen in Figure 11. The strain gauges were also mounted per the protocol in Appendix I. 


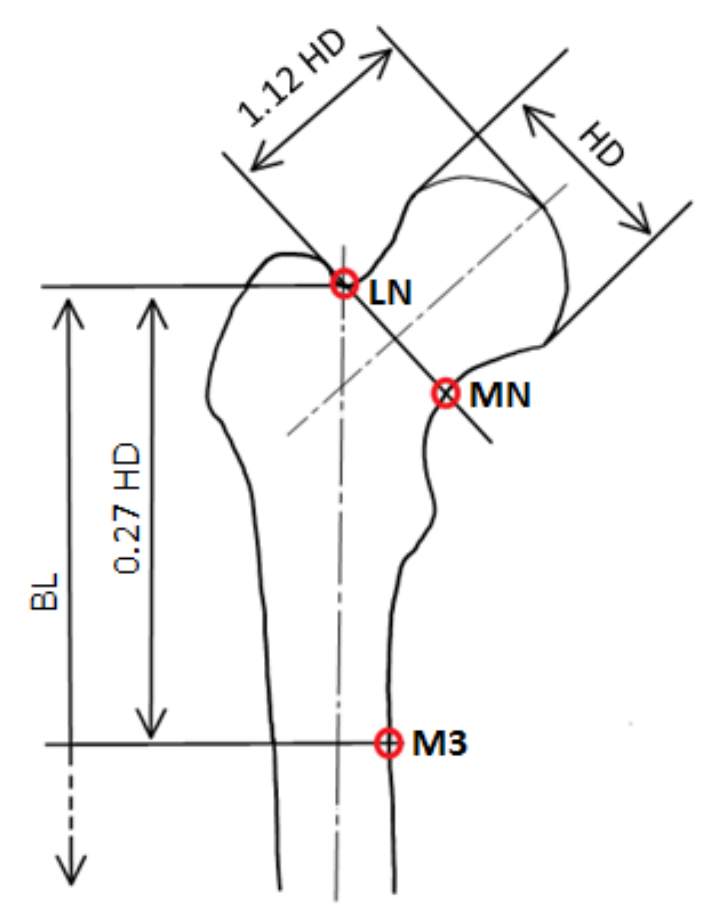

FIGURE 11 - Strain gauge placement was based off of the work of Zani et al. (2015).

Three critical locations were chosen as Lateral Neck (LN), Medial Neck (MN) and Medial Shaft (M3). These placements were determined based on the Head Diameter (HD), and Biomechanical Length (BL).

Next, an artificial hip was created using a wooden block with an appropriate size $(63.5 \mathrm{~mm})$ drill hole, similar to that of an acetabulum (Figure 12). Plastic/PVC tubing was used to ensure a tight fit of the femoral head but allowing relatively low friction movement mimicking an actual hip joint. The artifical acetabulum fixture was secured to a table and the exercise device was placed above, simulating the realistic positioning as much as possible.

Since only one femur was used in the experiment (as opposed to both legs being abducted simultaneously in the exercise), one side of the bar was secured to the table with a vice. To simulate the soft tissue of the outer thigh a viscoelastic rubber cube was used with properties similar to soft tissue. This cube was placed in between the sawbone femur and the pad. 


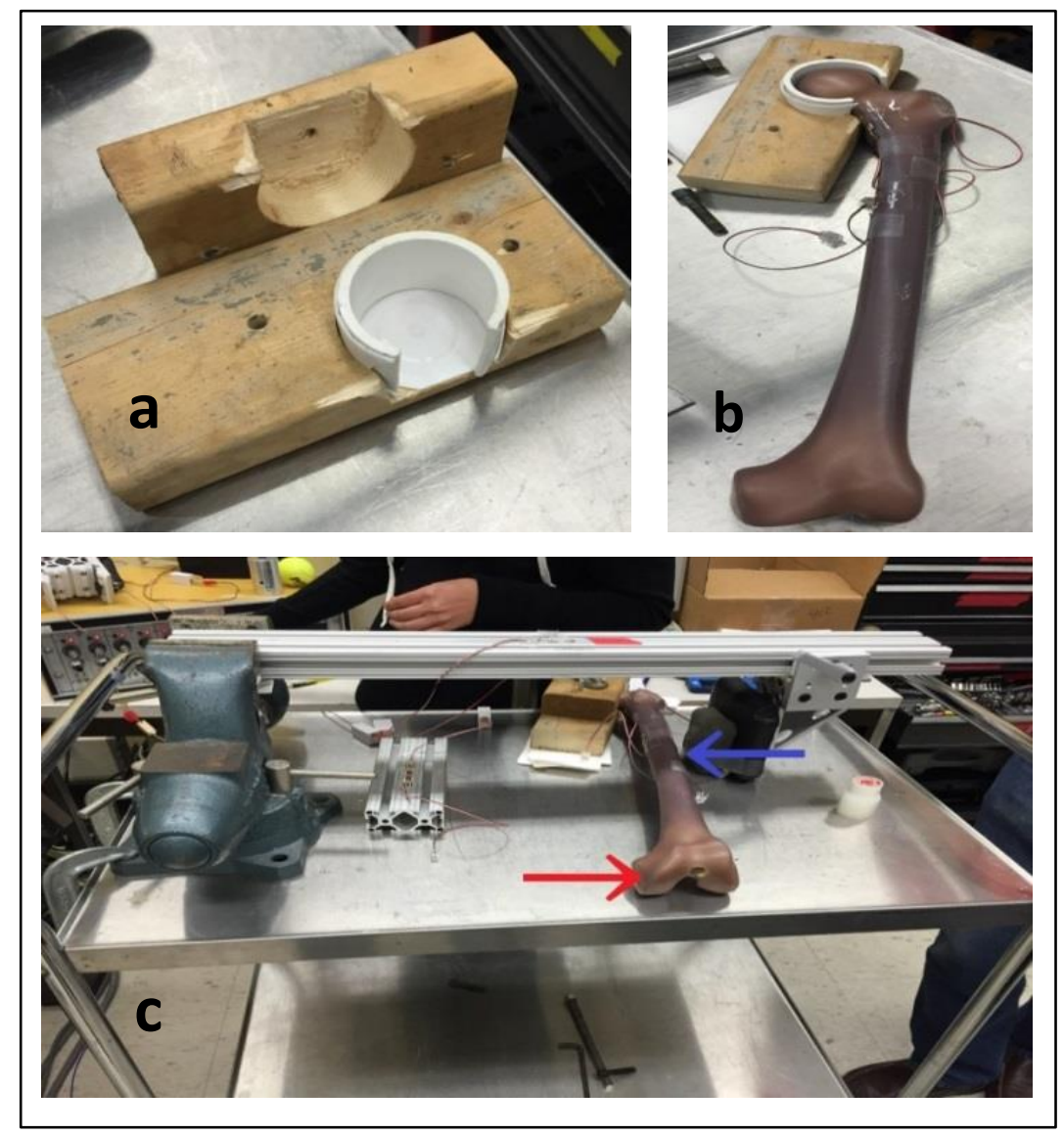

FIGURE 12 - Set of the sawbone experimentation, including (a) an artificial hip, (b) an instrumented sawbone positioned into the artificial hip and (c) overall set-up for simulating the exercise.

The knee of the sawbone was then manually manipulated to simulate the motion of the exercise. With both condyles flat on the table, an operator pushed the knee outward so that the femur impacted the soft tissue/pad and then returned to the neutral start position. This was repeated at intensities that matched the 350-550N ranges described previously. By using the strain gauge's specifications and measuring the votage across the gauges, strains vaules were simultaneously recorded at $1000 \mathrm{~Hz}$ at the three locations of the femur. 


\section{E. Ex-vivo Cadavaric Femur Experiment}

Understanding that a sawbone is an approximation of the size and shape of a femur for the general population, with properties relative to bone, the previous experiment better represted a healthy adult with good bone quality performing the exercise. Therefore, in order to observe the strain distributions during the exercise in our target population of osteoportic patients, the experiment was repeated using an explanted cadaver femur from an elderly female donor (Figure 13). The explanted cadaver femur was instrumented using the same placement and mounting protocols as the previous experiment. The femur was placed in the same artificial hip with an additional PVC spacer to ensure a tight fit on the smaller femoral head and the exercise was simulated and results recorded in the same way as the sawbone experiment.
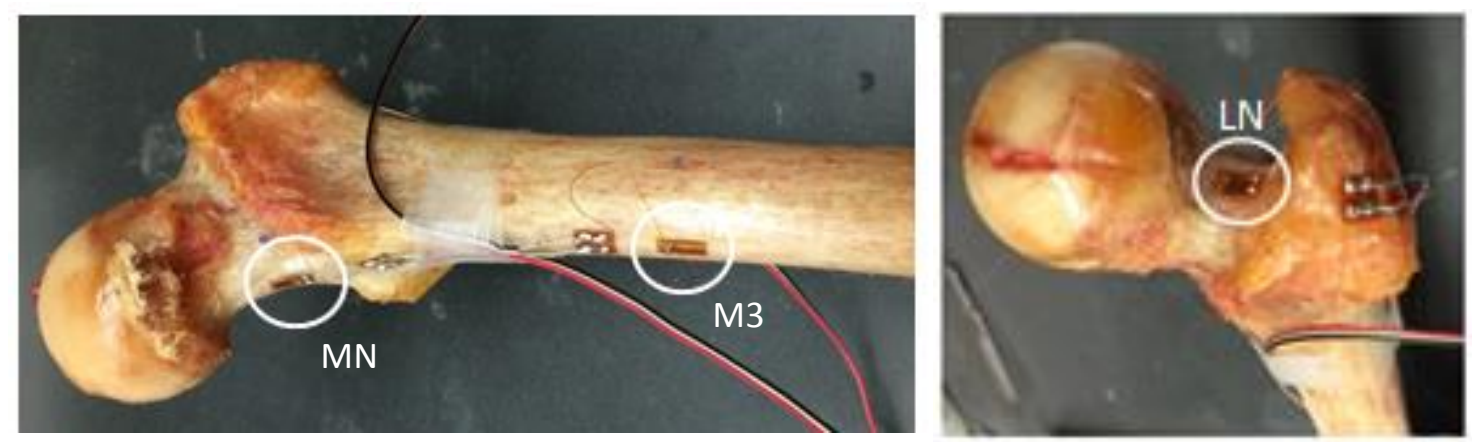

FIGURE 13 - Placement of the three strain gauges M3, MN, and LN on the explanted cadaver femur.

\section{F. In-Situ Cadaver Experiment}

With the goal of simulating the exercise with even more accuracy, the experiment was repeated in a whole cadaver. This incorperates the inertial effects of the mass of the soft tissue, as well as the effects of connective tissue 
and ligaments (granted inactive, but still present), and both legs abducting simultaneouly.

In order to accomplish this, a Kocher-Langenbeck surgical approach was used to access to the superior-lateral femoral neck. A strain gauge was placed in the LN location, similar to the previous experiments. Since the lateral neck is the most critical location of stress, only this strain gauge was assessed in this experiment in order to limit any further disruption of the surrounding anatomy.

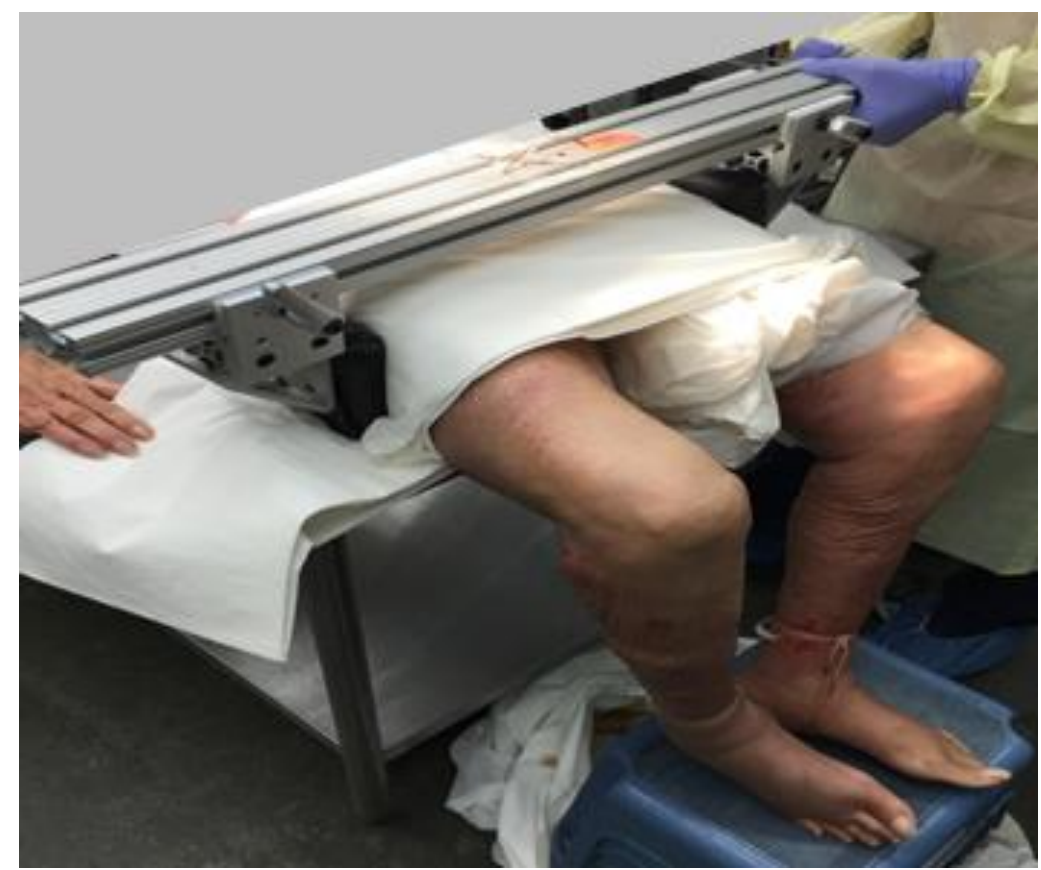

FIGURE 14 - The in-situ cadaver experimental setup.

The cadaver was placed in an upright sitting position with the lower legs draped over the table and feet propped on a stool, the exercise device was placed in the proximal position (Figure 14), and the knees were manually abducted outward so that the outer thighs impacted the pads at the appropriate intensity. Force and strain results were recorded the same way as the previous two experiments. 


\section{G. In-Silico Computational Solidworks Model}

In order to evaluate the strains occurring throughout the femur and not only the three specific locations of the experimental strain gauges, a computational FEA model was created to determine safety and effectiveness of the exercise, as well as to optimize pad material properties and location of impact of the femur.

\section{Model \& FEA}

A SolidWorks computational model made from the CT scan of the cortical shell of a sawbone was used for the FEA. In order to allow for frictionless movement of the femoral head in the acetabulum, a portion of the femoral head which interacts with the acetabulum was replaced with a perfect spherical face (Figure 15a). Additionally, a corresponding spherical acetabulum was made and fixed in space (Figure 15b, Figure 17a). To prevent rotation of the knee, the two lateral surfaces of the condyles were only allowed to move along the top plane of the model (Figure 17c).

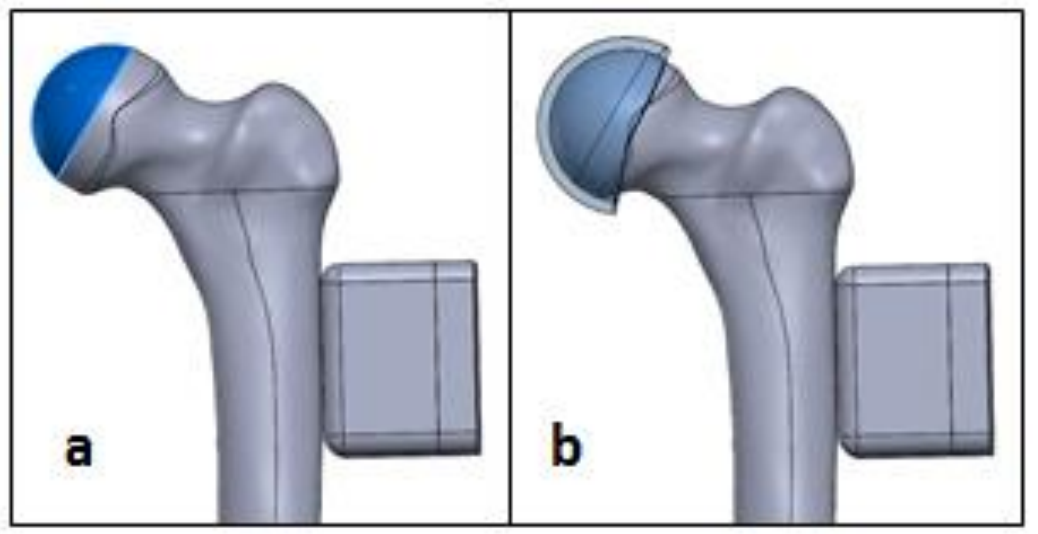

FIGURE 15 - Alterations made to the model include (a) making a portion of the femoral head spherical and (b) adding a corresponding spherical acetabulum. 
A two part pad was designed where section A was representative to the size, shape and material properties of the imitation soft tissue cube used in experimentation, and section $B$ representative of the pad of the exercise device (Figure 16). To prevent movement of the pad, the back surface of the section B was fixed in space (Figure 17b).

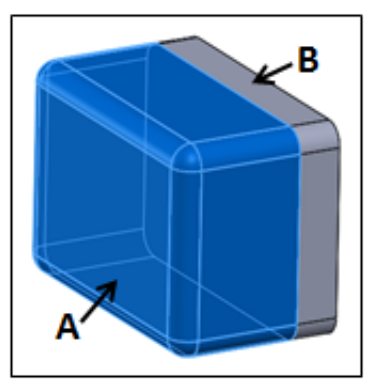

FIGURE 16 - The design of the two part pad including a representation of the soft tissue (A) and the pad (B).

A no-penetration boundary condition was set between the femoral head and the acetabulum, and between the femur and the soft tissue/pad. Section A and $\mathrm{B}$ of the pad were bonded together.

The pad was positioned the same as in the experimentation, proximally on the femur, between $90 \mathrm{~mm}-95 \mathrm{~mm}$ below the top of greater trochanter. For modeling purposes, the starting position of the femoral shaft was $1.0 \mathrm{~mm}$ away from the pad to allow the impact to be observed, whereas the proposed exercise starts with the pad slightly pre-compressed on the thighs. 


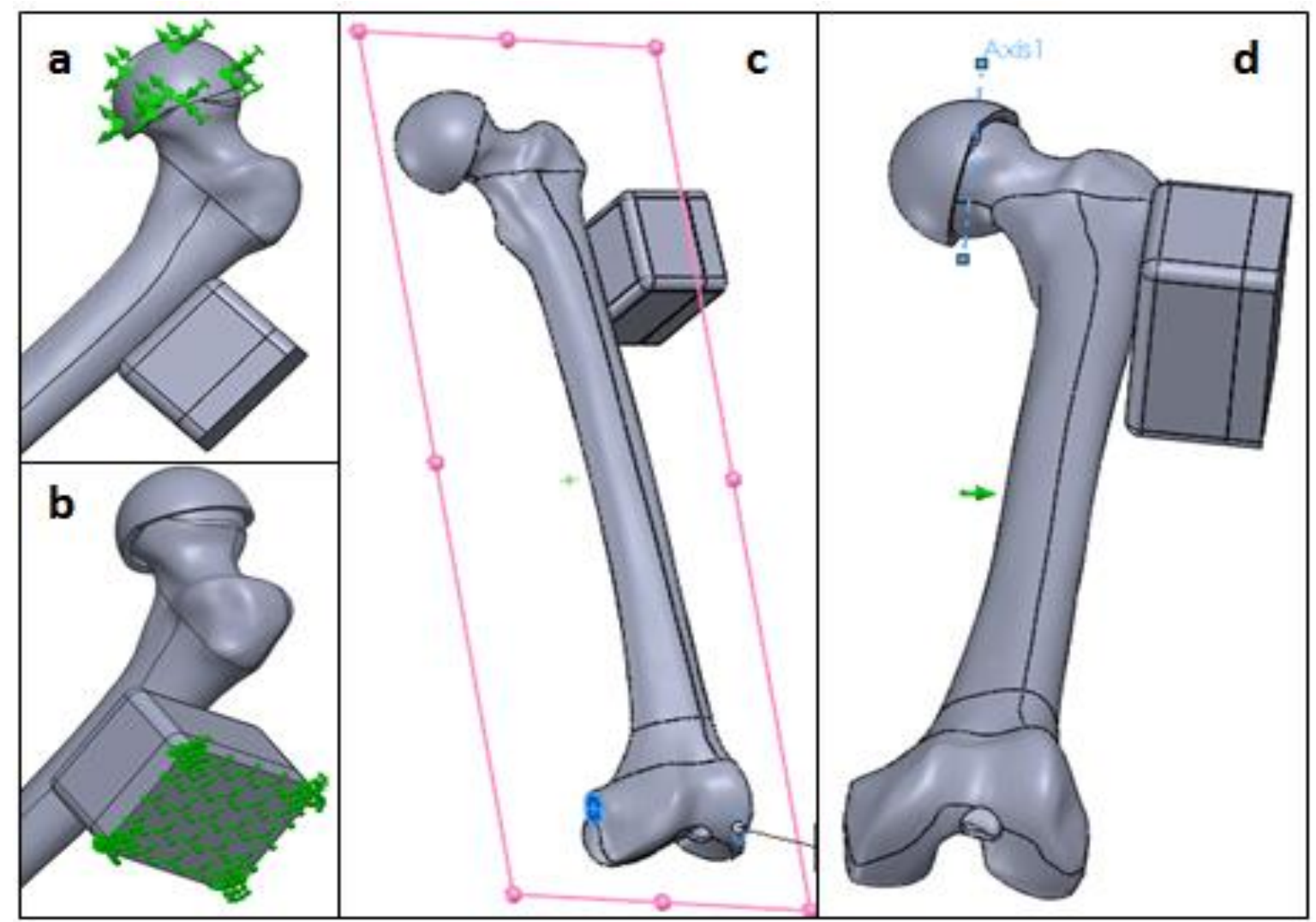

FIGURE 17 - Boundary condition of the FEA model: (a) the outer surface of the acetabulum fixed in space, (b) the back surface of pad fixed in space, (c) the lateral faces of the condyles restricted to movement normal to the top plane only. Also, the externally applied forces including (d) the initial angular velocity applied to the entire femur in rotation around Axis 1.

In order to simulate the motion of the exercise, an initial angular velocity was applied to the entire femur with center of rotation set as the axis in the center of the femoral head (Figure 17d). The angular velocity of $4.7 \mathrm{rad} / \mathrm{s}$ was chosen based on the results of the kinematic experiments performed earlier. Once the femur impacted the pad it was allowed to bounce back respectively based on the boundary conditions and material properties set.

A nonlinear-dynamic, Large Problem Direct Sparse solver was used with Large Displacement and Large Strain Formulation. A high quality, solid, curvature based mesh with 4 Jacobian points was used (Figure 18). Maximum 
element size was $8.0 \mathrm{~mm}$ and minimum element size was $1.6 \mathrm{~mm}$, totaling $>37,500$ elements with maximum aspect ratio 31.9. Data was stored at $1000 \mathrm{~Hz}$.

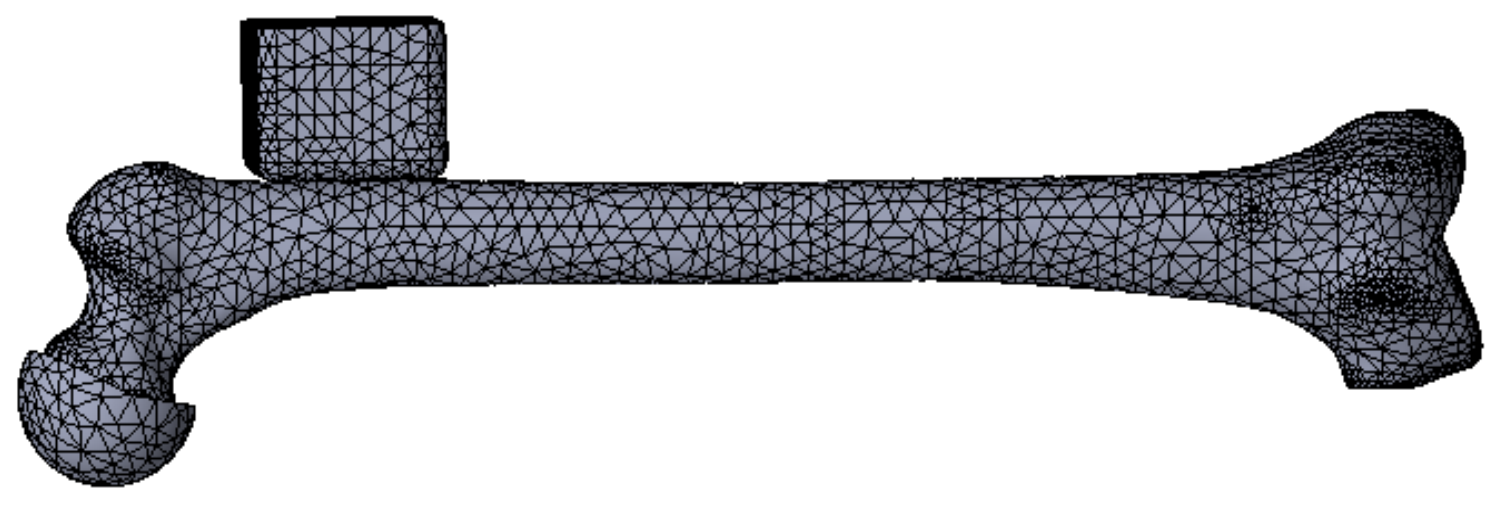

FIGURE 18 - Mesh results of the FEA model.

Sensors for measuring strains were included in the model by selecting elements at the locations of the strain gauges (Figure 19) by following Zani's (2010) protocol. First principal strain results were used to find maximum tensile strains, and third principal strains results were used to find maximum compressive strains.

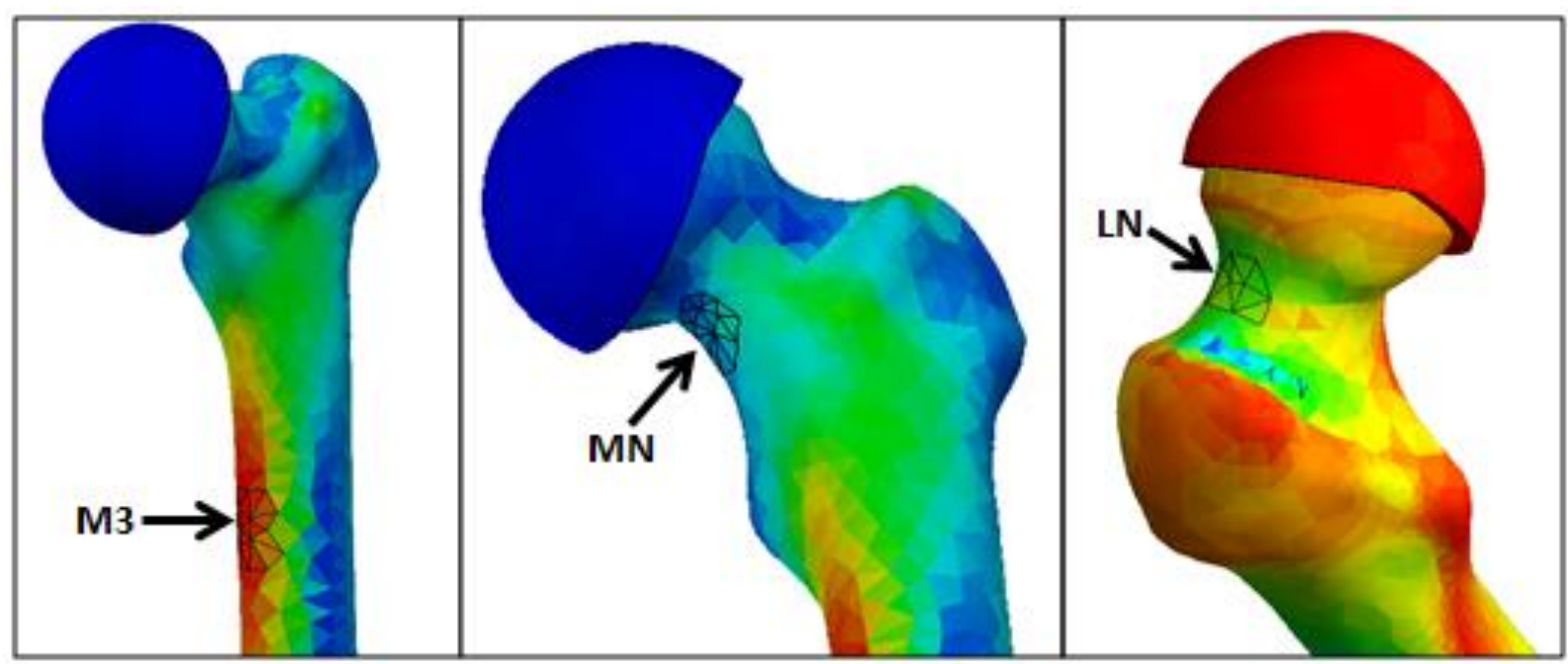

FIGURE 19 - Location of three sensors M3, MN and LN in the FEA model that correspond to the experimental strain gauge placement. 
Three versions of the model were created so that the results of the sensors could be directly compared to the results of the strain gauges in the experimentation and therefore validate the model.

\section{Sawbone FEA}

The material properties of the femur and the acetabulum were based on $4^{\text {th }}$ generation sawbone material properties that can be seen in Table II.

TABLE II

SAWBONE MATERIAL PROPERTIES

\begin{tabular}{|l|l|}
\hline Elastic Modulus & $16 \mathrm{GPa}$ \\
\hline Poisson's Ratio & 0.3 \\
\hline Mass Density & $1640 \mathrm{~kg} / \mathrm{m}^{2}$ \\
\hline Tensile Strength & $100 \mathrm{MPa}$ \\
\hline Compressive Strength & $157 \mathrm{MPa}$ \\
\hline
\end{tabular}

\section{Cadaveric Femur FEA}

For the second version of the model the bone material properties changed to represent poor quality bone to better reflect to the cadaver bone used as well as the target population (Table III). However, the geometry of the model remained the same, which could cause variation in the results since thinner cortical walls could elicit more strains in certain area like the superior-lateral neck. The same initial velocity and boundary conditions were applied.

TABLE III

POOR QUALITY BONE MATERIAL PROPERTIES

\begin{tabular}{|l|l|}
\hline Elastic Modulus & $11.5 \mathrm{Gpa}$ \\
\hline Poisson's Ratio & 0.3 \\
\hline Tensile Strength & $95 \mathrm{MPa}$ \\
\hline Compressive Strength & $100 \mathrm{MPa}$ \\
\hline
\end{tabular}




\section{4. $\underline{\text { Cadaver FEA }}$}

Compared to the previous models where only the femur was represented, the in-situ cadaver experiment includes the effects of the mass of the soft tissue. Since in the proposed exercise and the cadaver experiment the feet are supporting the mass of the lower legs, thus the mass of the upper legs is what contributes to increased inertial effects. So in order to account for these differences in the model, the density of the femur was increased to represent the weight of the entire upper leg $(6.22 \mathrm{~kg})$. Since the cadaver was a smaller elderly female, this weight was taken from anthropometric data on the $5^{\text {th }}$ percentile female population (Appendix II), which is also representative of the target population. The material properties representing poor bone quality remained the same and the same initial velocity and boundary conditions were applied.

\section{Optimization}

In order to design the exercise to elicit as much strain in the critical location of the superior-lateral neck as possible, the effects of: pad placement, pad material properties, and applied force were investigated.

The pad was placed at 3 different locations $(80 \mathrm{~mm}, 100 \mathrm{~mm}$, and $120 \mathrm{~mm}$, below the top of the greater trochanter) along the lateral side of the femur and strains at the three critical locations were evaluated (Figure 20). Material stiffness properties were also altered and resulting strains assessed. 

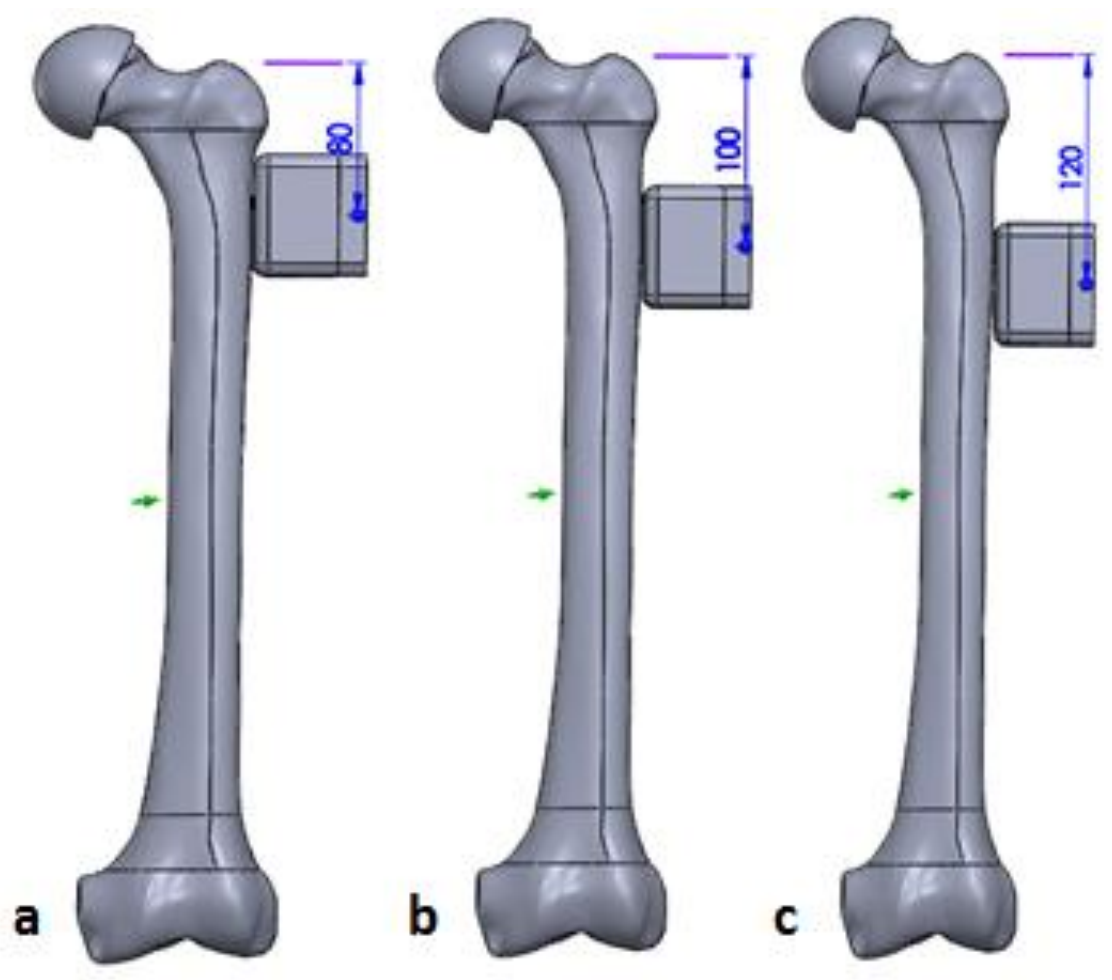

Figure 20 - Pad placement at a) $80 \mathrm{~mm}$ b) $100 \mathrm{~mm}$ and c) $120 \mathrm{~mm}$ below the top of the grater trochanter.

\section{Safety \& Effectiveness}

The importance of the computer model was not only to compare the results of the experiments to a general femur model to optimize the experiment, but also to evaluate the strains throughout the femur and not just the three locations measured experimentally. By doing so, the areas that are likely to be remodeled can be identified and it can be assured that the proposed exercise at the suggested intensities will not cause harm to the patients. Therefore, the stresses and strains calculated by the model were compared to the laws of remodeling and to known fracture limits. 


\section{RESULTS}

\section{A. Artificial Sawbone Data}

For the artificial sawbone experiment at impacts of $450 \mathrm{~N}$, the corresponding strains were $\mathrm{LN}=-367.5 \mu \varepsilon, \mathrm{M} 3=838.1 \mu \varepsilon$, and $\mathrm{MN}=456.3 \mu \varepsilon$. Average strain rates were $L N:-7,518 \mu \varepsilon / \mathrm{s}(S D=1388), M 3: 17,474 \mu \varepsilon / \mathrm{s}(S D=835)$, $M N: 12,871 \mu \varepsilon / s(S D=1149)$. The highest tensile strains were measured in the medial shaft across from the pad where the cortex was subjected to the most bending. Lateral neck strains were in compression and the medial neck strains were in tension, which indeed replicates the loading condition of a fall to the side.

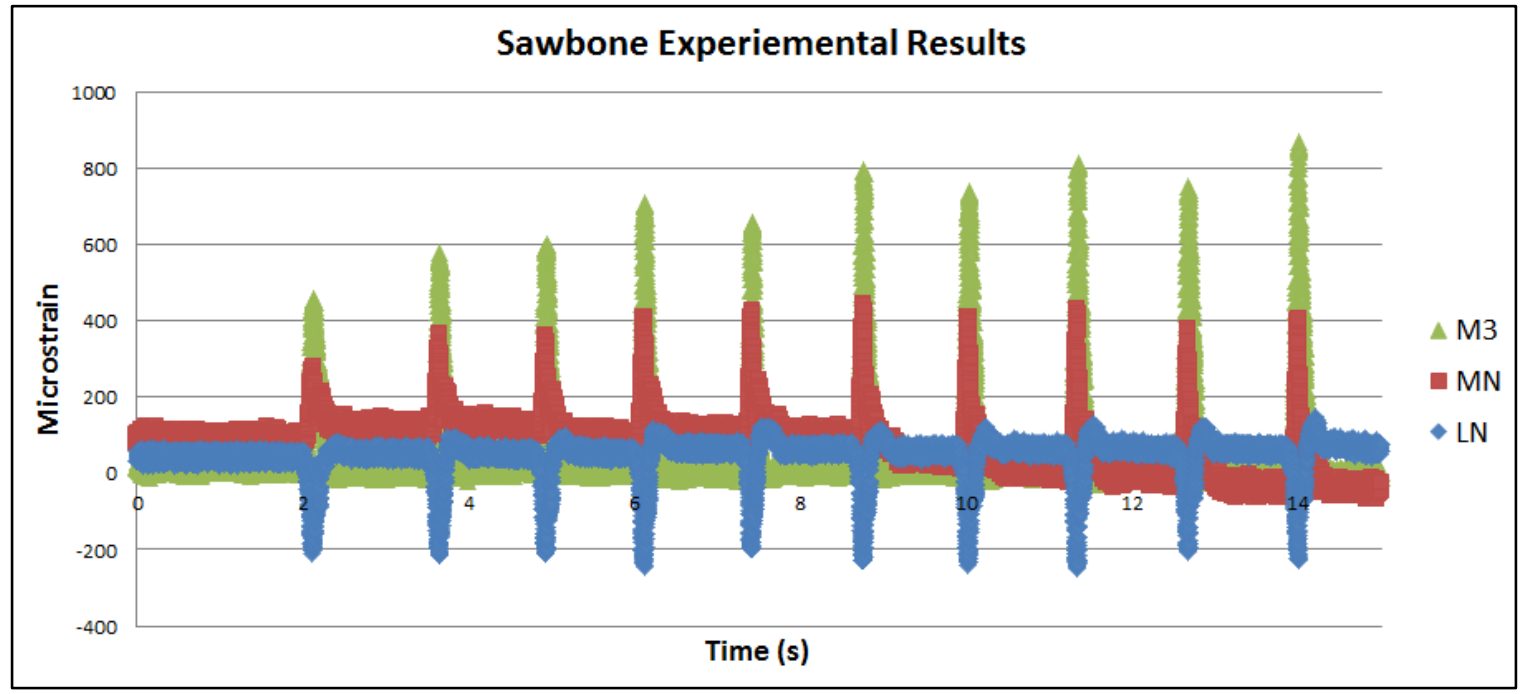

FIGURE 21 - Strain gauge results for the artificial sawbone experiment, including ten different impacts of the pad (impacts ranging from 350-550N of applied force) for all three strain gauges $\mathrm{M} 3, \mathrm{MN}$ and $\mathrm{LN}$. 
In order to evaluate the accuracy of the FEA model a percentage (D) was calculated to compare the experimental strain values $(E)$ to the computational FEA strain values $(C)$.

$$
D=\left[\frac{|E-C|}{E}\right] \times 100
$$

For the sawbone FEA, both medial shaft (M3) and lateral neck (LN) strain values were within $2.5 \%$ of the experimental data $(858.4 \mu \varepsilon$ and $-376.78 \mu \varepsilon$ respectively) (Figure 22).

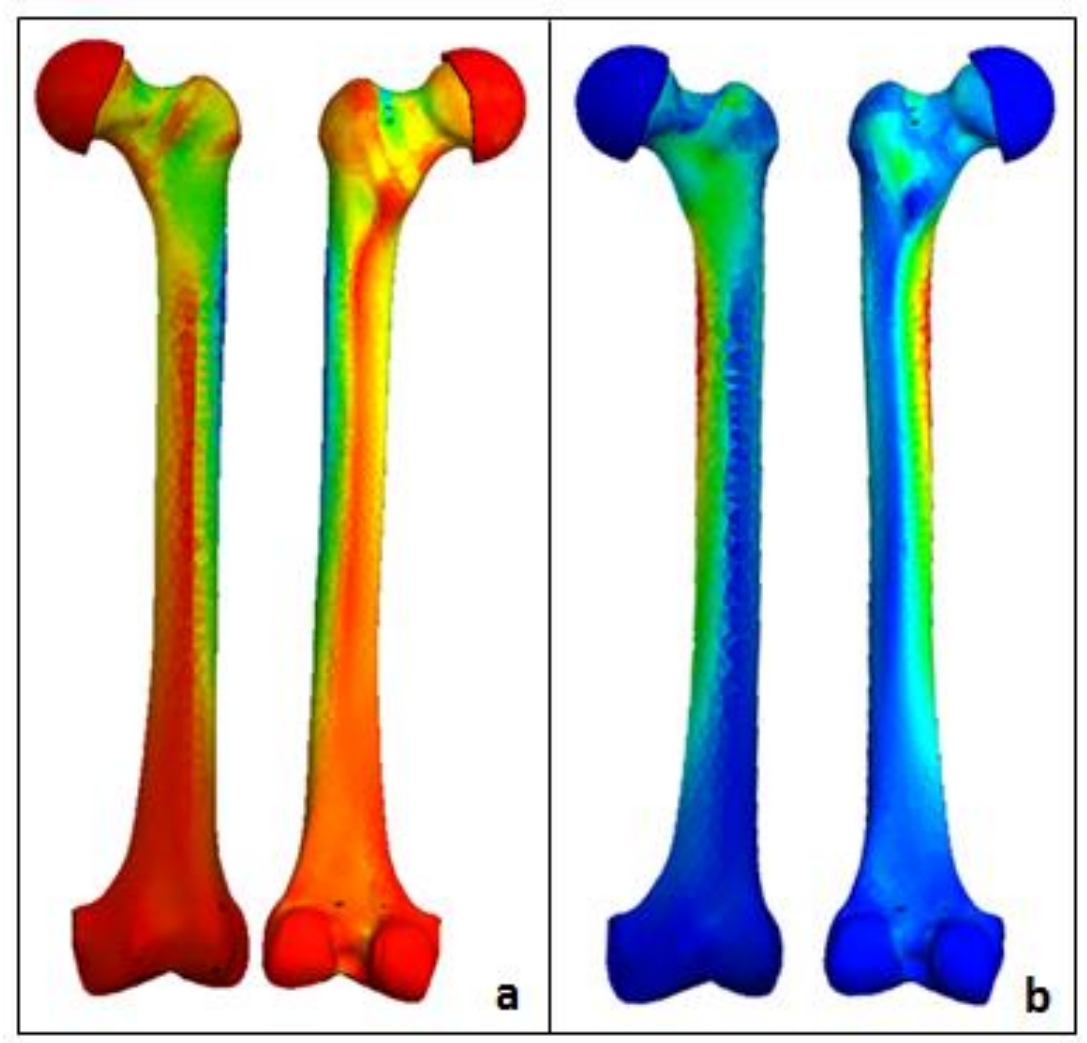

FIGURE 22 - Anterior (left) and posterior (right) view of the artificial sawbone FEA results of (a) $3^{\text {rd }}$ principal compressive strains and (b) $1^{\text {st }}$ principal tensile strains.

However the medial neck $(\mathrm{MN})$ had $44 \%$ less strain $(255.6 \mu \varepsilon)$ in the model than measured in the experiment. This discrepancy can be explained by 
experimental off-axis loading. While performing the experiment, as the operator abducted the knee to impact the pad, there was likely some inadvertent distraction of the knee that could lead to increased experimental tensile strains in the medial neck. Since the artificial acetabulum encompasses the entire femoral head, any distention that would be applied while abduction occurred would magnify these tensile strains. To test this assumption, a force was applied to the FEA model in the appropriate direction and it appears that the medial neck is roughly $2 / 3$ more sensitive to this distention than the lateral neck.

However, this distension would not occur in the actual exercise, and for that reason the FEA model of the exercise utilizes only pure rotational velocity, with the only distention influence due to mass and inertia. Thus, this theory explains why the FEA model results had less strain than the experiments, and it's concluded that the FEA model medial neck strains would be more accurate than what was captured during the experimentation. This explanation could be further tested by intentionally axially distracting and compressing the femur during the experiment to determine the effects on femoral neck strains.

Another important factor that the FEA model revealed is that the locations of the strain gauges/sensors did not necessarily capture the maximum strain values in their regions. This suggests that strain amplitudes were actually higher than what was recorded experimentally. In the sawbone model peak strains were $26.2 \%$ higher $(322.6 \mu \varepsilon)$ in the medial neck, and $91.6 \%$ higher $(-722.1 \mu \varepsilon)$ in the superior-lateral neck (Figure 23) than what was measured by the sensors. The medial shaft sensor did capture the peak strains in the shaft $(858.7 \mu \varepsilon)$. 


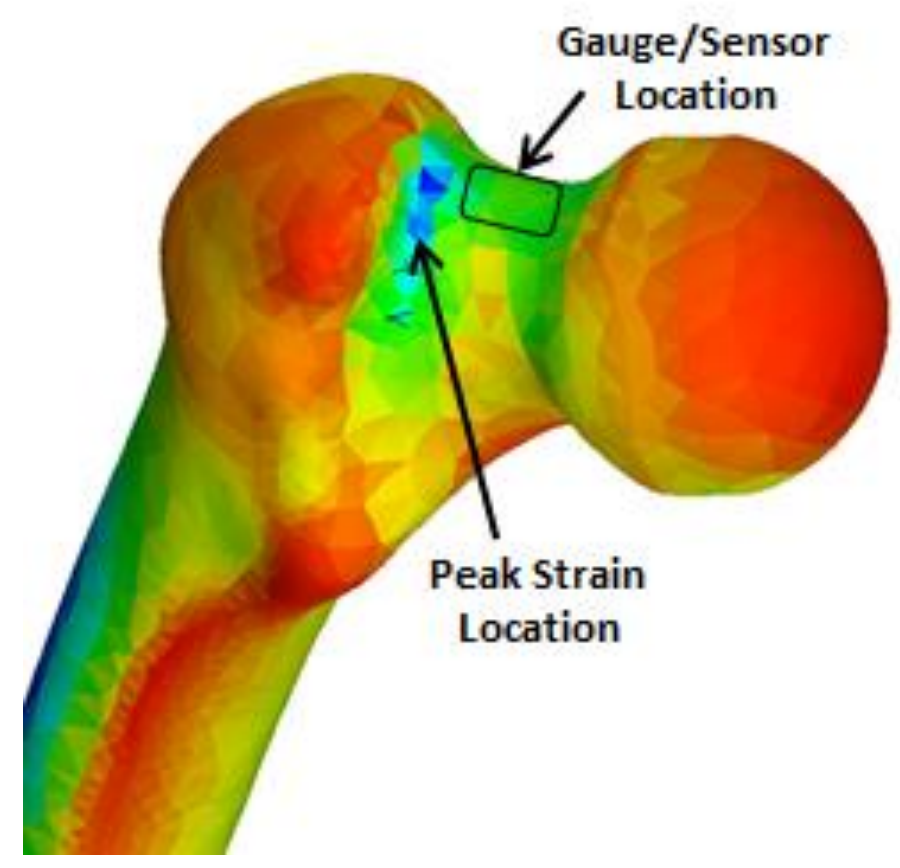

FIGURE 23 - FEA compressive strain results showing peak strain location in the lateral neck is not within the gauge / sensor location.

\section{B. Ex-Vivo Cadaveric Femur Data}

For the following ex-vivo cadaveric femur experiment, strain magnitudes at $450 \mathrm{~N}$ impacts were $\mathrm{LN}=-766.5 \mu \varepsilon, \mathrm{M} 3=1100.9 \mu \varepsilon$, and $\mathrm{MN}=589.1 \mu \varepsilon$, Average strain rates were $L N: 14,910 \mu \varepsilon / s(S D=2138), M 3: 22,937 \mu \varepsilon / s(S D=2417), M N$ : $13,379 \mu \varepsilon / \mathrm{s}(S D=2054)$. These strains magnitudes were $108.5 \%, 31.4 \%$ and $29.1 \%$ higher, respectively, than the sawbone strain results. Additionally, the strain magnitudes were considerably higher in the lateral neck which reached $69.6 \%$ of the strains in the medial shaft, as compared to $43.8 \%$ in the sawbone model. This can be explained by the lower bone quality, and thinner superior cortex of the elderly cadaveric specimen as compared to the representative healthy sawbone. 
For the FEA results that represent the ex-vivo cadaver experiment, the medial shaft strains at the sensors $(M 3=1114.2 \mu \varepsilon)$ were within $2 \%$ of the experimental strains however, as expected the medial neck $(M N=252.9 \mu \varepsilon)$ and lateral neck $(\mathrm{LN}=-430.12 \mu \varepsilon)$ strain values at the sensors were significantly lower than experimental strains; this may also be in part due to experimental off-axis loading, but most likely due to the anatomical geometry differences between the cadaver femur and the model. Since the model is based on the cortical shell of a sawbone, the cadaver femur is likely to have a much thinner cortical wall within the femoral neck, especially in the superior-lateral neck. This would correlate to much higher experimental strains in the femoral neck of the cadaveric bone, but would not be reflected in the model. However, even without the reduced wall thickness, peak strains in the supero-lateral neck of the FEA model still reached over $850 \mu \varepsilon$.

\section{In-Situ Cadaver Data}

Lastly, the in-situ cadaver experimental strains at a realistic $450 \mathrm{~N}$ impacts were $L N=-1511.3 \mu \varepsilon$ with a strain rate of $36,954 \mu \varepsilon / \mathrm{s}(S D=8933)$. This is over four times the strain magnitude seen in the lateral neck of the sawbone experiment and while this was predicted to be larger due to the added mass and inertial effects, it is also expected to be the most accurate strain representation of all three experiments. These strain magnitudes and strain rates are within the remodeling range and suggest that this exercise at this intensity could produce an anabolic remodeling response in the lateral femoral neck. 
Similarly, after the computer model was changed to represent the in-situ cadaver which included the mass of the upper leg, strains in all three locations increased significantly. It only took an applied $4 \mathrm{rad} / \mathrm{s}$ of initial velocity in the FEA to reach $1500 \mu \varepsilon$ at the sensor location in the lateral neck which is within $1 \%$ of the in-situ cadaver experimental data for a $450 \mathrm{~N}$ force. Peak strains were $3217.6 \mu \varepsilon$ in the medial shaft, $1589 \mu \varepsilon$ in the medial neck and $-2736.7 \mu \varepsilon$ in the lateral neck. These strain magnitudes are well above the strains needed to achieve remodeling.

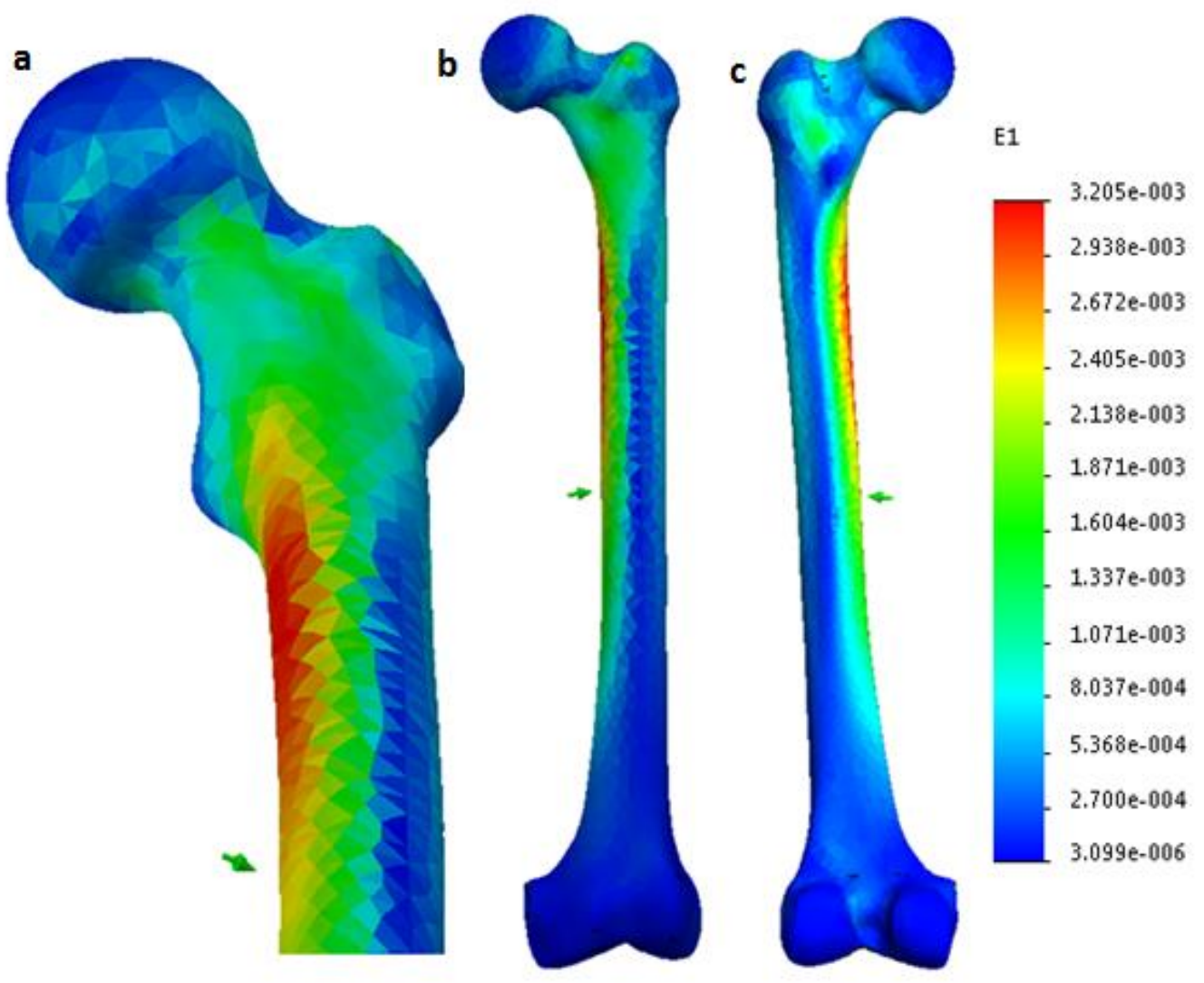

FIGURE 24 - FEA tensile strain results for a) the peak medial neck and shaft strains, b) anterior view and c) posterior view of the femur. 


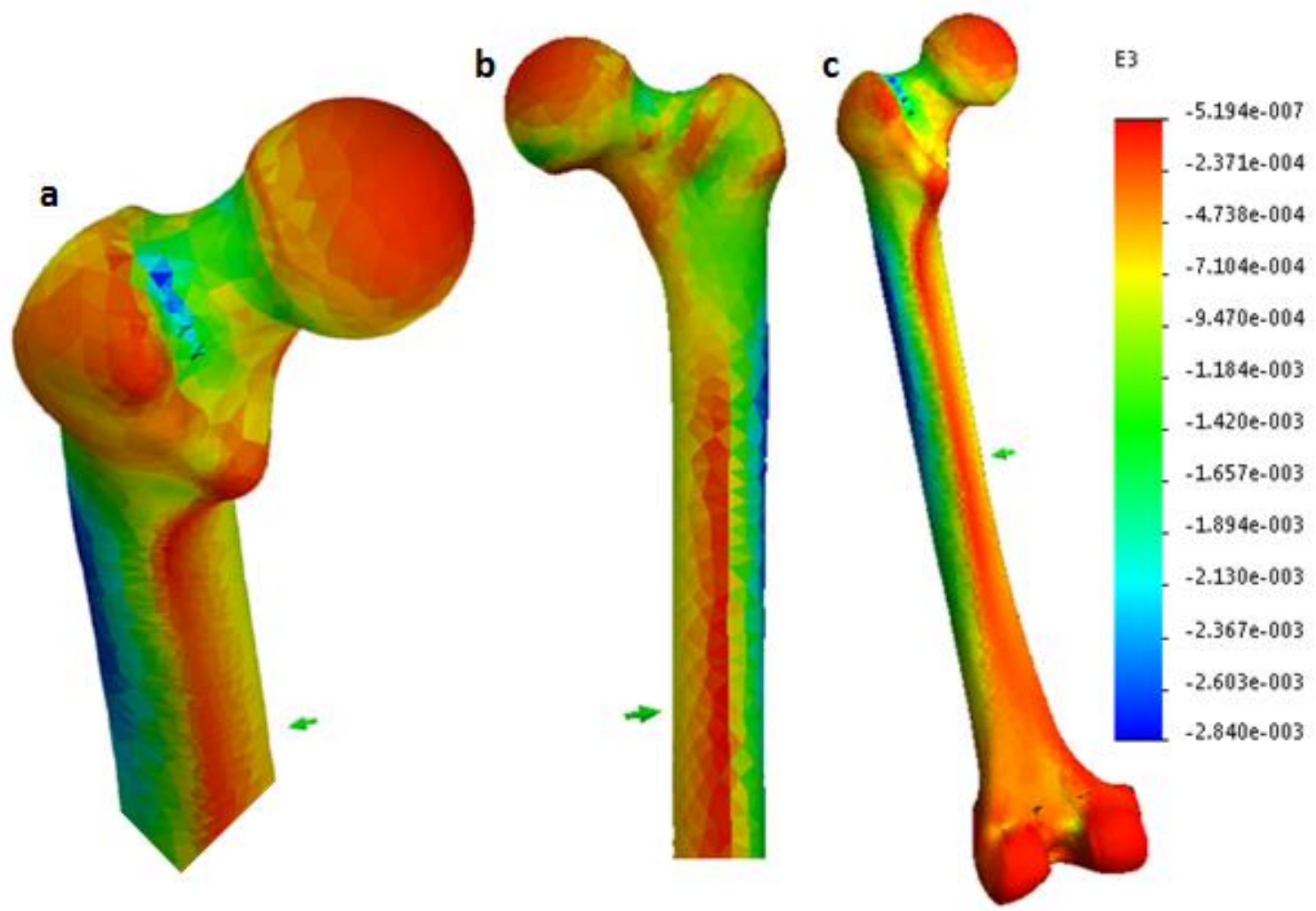

FIGURE 25 - FEA compressive strain results for a) the peak lateral neck strains, b) anterior view and c) posterior view of the femur.

\section{Optimization}

Due to the thickness of the imitation soft tissue block used in the experiments, most of the interaction happened between the femur and the soft tissue and therefore, varying the pad properties (without varying the soft tissue properties) had little to no effect on strain in the FEA model. However, the amount of soft tissue will vary depending on the user and therefore when designing the final pad, material properties will need to be considered. For maximizing the strain results, the pad should be as stiff as possible; however, this needs to be carefully balanced with comfort of the exercise. The users should be able to achieve the amount of force applied to the pads as described in 
this paper, without causing harm or discomfort. In the same way, while a smaller contact surface would be ideal for maximizing strain; surface area of the pad will also need to be designed for comfort and prevention of soft tissue damage and bruising.

Pad placement did have a significant effect on strain distribution. The model was simulated with the added weight of the upper leg at a soft, comfortable impact intensity of $3.2 \mathrm{rad} / \mathrm{s}$ at three different locations of the pad $(120 \mathrm{~mm}, 100 \mathrm{~mm}$ and $80 \mathrm{~mm}$ from the top of the greater trochanter). These results can be seen in Table IV. Peak strains in the shaft, medial neck and lateral neck were all greater than $1500 \mu \varepsilon$ but below $3000 \mu \varepsilon$. As the pad was moved more proximally, peak tensile strains in the shaft and medial neck decreased whereas the peak compressive strains in the lateral neck increased. Therefore, the pad placed more proximally is the most ideal location since it maximizes the lateral neck strains and minimizes the shaft strains.

TABLE IV

STRAIN RESULTS AT DIFFERENT PAD PLACEMENTS

\begin{tabular}{|c|c|c|c|}
\hline & $\mathbf{8 0 m m}$ & $\mathbf{1 0 0 \mathbf { m m }}$ & $\mathbf{1 2 0} \mathbf{m m}$ \\
\hline Shaft & $2467.3 \mu \varepsilon$ & $2550.1 \mu \varepsilon$ & $2741.6 \mu \varepsilon$ \\
\hline Medial Neck & $1507.6 \mu \varepsilon$ & $1548.4 \mu \varepsilon$ & $1570.6 \mu \varepsilon$ \\
\hline Lateral Neck & $-2451.6 \mu \varepsilon$ & $-2273.5 \mu \varepsilon$ & $-2268.6 \mu \varepsilon$ \\
\hline Ratio M3 : LN : MN & $1.00: 1: 0.6$ & $1.12: 1: 0.68$ & $1.20: 1: 0.69$ \\
\hline
\end{tabular}

E. Proof of Concept: Safety and Effectiveness

The results outlined in Table $V$ suggest that the proposed exercise, even at a soft comfortable impact range, can reach remodeling strain magnitudes in 
most of the lateral neck, with peak strains reaching $-2451.6 \mu \varepsilon$. At the optimal position (with the pad as proximal as possible), peak strains in the remainder of the femur are below the fracture rate and are highest $(2467.3 \mu \varepsilon)$ in the medial shaft directly across from the pad. If the pad is moved more distally the strains in lateral neck decrease, but are still within the remodeling window, and the strains in the shaft increase. At high intensities this may enter the shaft into the remodeling window $(>3100 \mu \varepsilon)$ that can cause microdamage and promote woven bone formation, however, these impacts are still well below the fracture limit $(>25,000 \mu \varepsilon)$

Based on bone mechanical stimulation animal literature, the experimental strain rates in the lateral neck are also high enough $(>10,000 \mu \varepsilon / s)$ to promote anabolic bone remodeling, and suggest that this exercise may be a valuable therapy for strengthening the proximal femur.

TABLE V

OVERVIEW OF RESULTS

\begin{tabular}{|c|c|c|c|c|c|c|c|c|c|}
\cline { 2 - 11 } & \multicolumn{3}{|c|}{ Sawbone } & \multicolumn{3}{c|}{ Ex-vivo Femur } & \multicolumn{3}{c|}{ In-situ Cadaver } \\
\cline { 2 - 11 } & $\begin{array}{c}\text { FEA Sensor } \\
\text { Strains }\end{array}$ & $\begin{array}{c}\text { Experiemental } \\
\text { Gauge Strains }\end{array}$ & $\begin{array}{c}\text { FEA Peak } \\
\text { Strains }\end{array}$ & $\begin{array}{c}\text { FEA Sensor } \\
\text { Strains }\end{array}$ & $\begin{array}{c}\text { Experiemental } \\
\text { Gauge Strains }\end{array}$ & $\begin{array}{c}\text { FEA Peak } \\
\text { Strains }\end{array}$ & $\begin{array}{c}\text { FEA Sensor } \\
\text { Strains }\end{array}$ & $\begin{array}{c}\text { Experiemental } \\
\text { Gauge Strains }\end{array}$ & $\begin{array}{c}\text { FEA Peak } \\
\text { Strains }\end{array}$ \\
\hline M3 & 858.4 & 838.1 & 858.7 & 1114.2 & 1100.9 & 1114.2 & 3205.3 & & 3217.6 \\
\hline MN & 255.6 & 456.3 & 322.6 & 252.9 & 598.1 & 374.0 & 1216.3 & & 1589.0 \\
\hline LN & -376.8 & -367.5 & -722.1 & -430.1 & -766.5 & -851.5 & -1499.2 & -1511.3 & -2736.7 \\
\hline
\end{tabular}

*All values in microstrain $(\mu \varepsilon)$ 


\section{DISCUSSION}
A. Limitations

The model was designed to get general strain distributions throughout the femur for the proposed exercise and was greatly simplified to be computationally effective in order to be able to process the data in a realistic timeframe. However, this model differs from the real experiment in several ways which could have an effect on the results. First, the model was based only on cortical bone, since this is the target of the research and the most likely to remodel, however it does not take into account the underlying effects of cancellous bone. Secondly, since the model had linear elastic isotropic material properties for the bone, it does not take into account the directional sensitivity of bone, nor does it take into account the viscoelasticity of bone tissue.

Also as explained earlier, the geometry of bone has a major role in strain distribution. However, the geometry of the femur can differ greatly between individuals and for that reason the sawbone was chosen for the computational model to represent the general population, but it needs to be understood that strains results have the possibility to vary greatly from patient to patient. Soft tissue will also have a significant effect on the exercise; it varies greatly between 
individuals and is very difficult to model with accuracy, which is why the imitation soft tissue block was used in these experiments. Additionally, bone material properties will likewise vary with individuals. Poor bone quality was used in these experiments and modeling in order to represent the population already entering the osteopenia/osteoporotic stages. Active muscle and ligaments will also have a powerful influence on the movement of the exercise, the force distribution and the impact, but because of its complexity, will realistically only be able to be evaluated in human trials.

\section{B. Considerations \& Future Development}

While the target population for this research are people likely to start loosing bone mass or those already in the osteopenia/osteoporotic stages, bone quality may already be diminished and may not be able to handle as much applied stress as a healthy bone. Thus, resultant strain values need to be well below the fracture limits for a healthy individual in order to ensure safety. It should be considered that users with poor bone health may not need to impact the pads as hard as those with healthier bone in order to achieve similar strain magnitudes in their exercise regimen.

Since the users are likely to be older individuals or those already in poor health, they may not have the ability to achieve the amount of force needed to impact the pads hard enough. For that reason further research and development is being done to create a device that will abduct the legs for the user, or use high frequency - low amplitude impacts directly to the greater trochanter to induce remodeling. A phone application utilizing the phone's accelerometer and 
gyroscope will be developed to measure the user's impact intensity to ensure they are in the correct ranges, as well as to measure the user's performance and frequency of use.

Pending completion of this research and development of the final devices, clinical trials will be performed to further evaluate the safety and efficacy of this exercise. This will be a prospective randomized controlled trial of volunteer subjects using the final device as part of a regular exercise program for six months. To evaluate bone formation, baseline pre-study measurement of bone mineral density by dual-energy $\mathrm{x}$-ray absorptiometry (DEXA) will be taken before the users start the exercise regimen and then again after six months of performing the exercise. Serum and/or urine markers of bone turnover will also be measured as well as abductor muscle strength and balance in one legstanding. Results will conclude if the exercise has a significant beneficial effect on bone quality in the superior-lateral region of the proximal femur. 


\section{CONCLUSION}

Preliminary experimental and FEA model results show that the proposed exercise has the potential to produce high enough strain magnitudes $(>1000 \mu \varepsilon)$ and strain rates $(>10,000 \mu \varepsilon / \mathrm{s})$ in the superior-lateral femoral neck in order to induce anabolic bone remodeling, while being well below the fracture limit in any area of the femur. This suggests that the proposed exercise could be a beneficial therapy for strengthening the proximal femur and may aid in the prevention of hip fractures. Subsequent steps to obtain IRB and FDA approval for clinical trials should now be initiated. 


\section{REFERENCES}

A.D.A.M. Health Solutions. "Osteoporosis" Internet Source, 5 November 2015, available https://medlineplus.gov/ency/imagepages/17285.htm; accessed 26 May 2017.

Astorino, T.A., Harness, E.T. \& Witzke, K.A. 2013. Effect of chronic activitybased therapy on bone mineral density and bone turnover in persons with spinal cord injury. Eur J Appl Physiol, 113(12), 3027-3037.

Bakker, P.M., Manske, S.L., Ebacher, V., Oxland, T.R., Cripton, P.A. \& Guy, P. 2009. During sideways falls proximal femur fractures initiate in the superolateral cortex: Evidence from high-speed video of simulated fractures. J Biomechanics, 42, 1917-1925.

Brauers, C.A., Coca-Perraillon, M., Cutler, D.M., Rosen, A.B. 2009. Incidence and Mortality of Hip Fractures in the United States. JAMA, 302(14), 15731579.

Brodt, M.D., \& Silva, M.J. 2010. Aged Mice Have Enhanced Endocortical Response and Normal Periosteal Response Compared With Young-Adult Mice Following 1 Week of Axial Tibial Compression. J Bone Miner Res, 25(9), 2006-2015.

Burge, R., Dawson-Hughes, B., Solomon, DH., Wong, J.B., King, A.. \& Tosteson, A. 2007. Incidence and Economic Burden of Osteoporosis-Related Fractures in the United States, 2005-2025. J Bone Miner Res, 22(3), 465475.

D’Angeli, V., Belvedere, C., Ortolani, M., Giannini, S. \& Leardini, A. 2013. Load along the femur shaft during activities of daily living. J Biomechanics, 46, 2002-2010.

Dierselhuis, E.F., Jutte, P.C., Van der Eerden, P.J.M., Suurmeijer, A.J.H., \& Bulstra, S.K. (2010). Hip fracture after radiofrequency ablation therapy for bone tumors: two case reports. Skeletal Radiol, 39, 1139-1143. 
Eckstein, F., Wunderer, C., Boehm, H., Kuhn, V., Priemel, M., Link, T.M. \& Lochmuller, E.M. 2004. Reproducibility and Side Differences of Mechanical Tests for Determining the Structural Strength of the Proximal Femur. J Bone Miner Res, 19(3): 379-385.

Farahmand, B.Y., Michaelsson, K., Ahlbom, A., Ljunghall, S., Baron, J.A. 2005. Survival after hip fracture. Osteoporos Int., 16: 1583-1590.

Friesendorff, M., McGuigan, F.E., Wizert, A., Rogmark, C., Holmberg, A.H., Woolf, A.D., Akesson, K. (2016). Hip fracture, mortality risk, and cause of death over two decades. Osteoporosis Int, 27, 2945-2953.

Fritton, J.C., Myers, E.R., Wright, T.M., \& Van der Meulen, M.CH. 2008. Bone Mass Is Preserved and Cancellous Architecture Altered Due to Cyclic Loading of the Mouse Tibia After Orchidectomy. J Bone Miner Res, 23(5), 663-671.

Frost, H.M. (1987). Bone "Mass" and the "Mechanostat": A Proposal. The Anatomical Record, 219, 1-9.

Frost, H.M. (2003). Bone's Mechanostat: A 2003 Update. The Anatomical Record, 275A, 1081-1101.

Hayes, W.C., Myers, E.R., Morris, J.N., Gerhart, T.N., Yett, H.S. \& Lipsitz, L.A. 1993. Impact near the hip dominates fracture risk in elderly nursing home residents who fall. Calcif Tissue Int, 52,192-198.

Helge, E.W., Andersen, T.R., Schmidt, J.F., Jørgensen, N.R., Hornstrup, T., Krustrup. P. \& Bangsbo, J. 2014. Recreational football improves bone mineral density and bone turnover marker profile in elderly men. Scand $\mathrm{J}$ Med Sci Sports, 24(1), 98-104.

Heron, Melonie. 2016. Deaths: Leading Causes for 2014. U.S. Department of Health and Human Services. Centers for Disease Control and Prevention. National Vital Statistic Report (NVSS), 65(5).

Huiskes, R. (2000). If bone is the answer, then what is the question?. J Anat, 197, 145-156. 
Huntjens, K.M.B., Kosar, S., van Geel, T.A.C.M., Geusens, P.P., Willems, P., Kessels, A., Winkens, B., Brink, P. \& van Helden, S. 2010. Risk of subsequent fracture and mortality within 5 years after a non-vertebral fracture. Osteoporos Int., 21(12), 2075-2082.

Jee, W.S.S. 2009. H. M. Frost's Legacy: The Utah Paradigm of Skeletal Physiology. The Niigata Journal of Health and Welfare 6(1), 1-9.

Judex, S., \& Rubin, C.T. 2010. Is bone formation induced by high-frequency mechanical signals modulated by muscle activity?. J Musculoskelet Neuronal Interact, 10(1), 3-11.

Kanis, J.A., McCloskey, E.V., Johansson, H., Oden, A., Melton III, L.J., \& Khaltaev, N. 2008. A reference standard for the description of osteoporosis. J Bone, 42, 467-475.

Kohrt, W.M., Ehsani, A., \& Birge, S.J. 1997. Effects of Exercise Involving Predominantly Either Joint-Reaction or Ground-Reaction Forces on Bone Mineral Density in Older Women. J Bone Miner Res, 12(8), 1253-1261.

Koivumäki, J.E.M., Thevenot, J., Pulkkinen, P., Kuhn, V., Link, T.M., Eckstein, F., \& Jämsä, T. 2012. Ct-based finite element models can be used to estimate experimentally measured failure loads in the proximal femur. $\mathrm{J}$ Bone, 50, 824-829.

Lang, T.F., Saeed, I.H., Streeper, T., Carballido-Gamio, J., Harnish, R.J., Frassetto, L.A., Lee, S.M.C., Sibonga, J.D., Keyak, J.H., Spiering, B.A., Grodsinsky, C.M., Bloomberg, J.J. \& Cavanagh, P.R. 2014. Spatial Heterogeneity in the Response of the Proximal Femur to Two Lower Body Resistance Exercise Regimens. J Bone Miner Res, 29(6), 13371345.

Narra, N., Nikander, R., Viik, J., Hyttinen, J. \& Sievanen, H. 2013. Femoral neck cross-sectional geometry and exercise loading. Clin Physiol Funct Imaging, 33, 258-266. 
Parkkari, J., Kannus, P., Palvanen, M., Natri, A., Vainio, J., Aho, H., Vuori, I. \& Järvinen, M. 1999. Majority of hip fractures occur as a result of a fall and impact on the greater trochanter of the femur: a prospective controlled hip fracture study with 206 consecutive patients. Calcif Tissue Int, 65(3): 183-7.

Pulkkinen, P., Eckstein, F., Lochmüller, E.M., Kuhn, V., \& Jämsä1, T. 2006. Association of Geometric Factors and Failure Load Level With the Distribution of Cervical vs. Trochanteric Hip Fractures. J Bone and Miner Res, 21(6), 895-901.

Rantalainen, T., Nikander. R., Daly, R.M., Heinonen, A. \& Sievänen, H. 2011. Exercise loading and cortical bone distribution at the tibial shaft. J Bone, 48(4), 786-91.

Robling, A.G., Duijvelaar, K.M., Geevers, J.V., Ohashi, N. \& Turner, H. 2001. Modulation of Appositional and Longitudinal Bone Growth in the Rat Ulna by Applied Static and Dynamic Force. J Bone, 29(2), 105-113.

Rubin, C., Gross, T., Qin, Y.X., Fritton, S., Guilak, F. \& McLeod, K. 1996. Differentiation of the Bone-Tissue Remodeling Response to Axial and Torsional Loading in the Turkey Ulna. J Bone and Joint Surgery, 78(10).

Rubin, C., Turner, A.S., Muller, R., Mittra, E., McLeod, K., Lin, W. \& Qin, Y.X. 2002. Quantity and Quality of Trabecular Bone in the Femur Are Enhanced by a Strongly Anabolic, Noninvasive Mechanical Intervention. J Bone Miner Res, 17(2): 349-357.

Shin, H.K., Choi, J.Y.,Lee,J., Jeong, H.J., Kim, E., Park S.J., Jeon, B., Lim, J.J. (2010). Lower Hip Bone Mass and Proximal Femur Fractures in Elderly Patients: More Valuable Than Lumbar Vertebrae Bone Mineral Density. Orthopedics, 33(12), 875.

Silva, M.J. \& Brodt, M.D. 2008. Mechanical Stimulation of Bone Formation is Normal in the SAMP6 Mouse. Calcif Tissue Int., 82(6): 489-497.

Stevens, J.A. \& Rudd, R.A. 2013. The impact of decreasing U.S. hip fracture rates on future hip fracture estimates. Osteoporos Int., 24: 2725-2728. 
Thompson, W.R., Rubin, C.T., \& Rubin, J. 2012. Mechanical regulation of signaling pathways in bone. J Gene, 503, 179-193

Treece, G.M., Gee, A.H., Mayhew, P.M., \& Pool, K.E.S. (2010). High resolution cortical bone thickness measurement from clinical CT data. J Medical Imaging Analysis, 14, 276-290.

Winter, D.A. 2005. Biomechanics and Motor Control of Human Movement, 3rd edition. John Wiley \& Sons.

Wolff J. 1892. The Law of Bone Transformation (Das Gesetz der Transformation der Knochen). Berlin, Germany: Verlag von August Hirschwald.

Yoshikawa, T., Turner, C.H., Peacock, M., Slemenda, C.W., Weaver, C.M., Teegarden, D., Markwardt, P., Burr, D.B., 1994. Geometric structure of the femoral neck measured using dual-energy X-ray absorptiometry. J. Bone Miner Res, 9, 1053-1064.

Zani, L., Cristofolini, L., Juszczyk, M.M., Grassi, L. \& Viceconti, M. 2014. A New Paradigm for the In Vitro Simulation of Sideways Fall Loading of the Proximal Human Femur. J Mechanics in Medicine and Biology, 14(1), 1450005.

Zani, L., Erani, P., Grassi, L., Taddei, F. \& Cristofolini, L. 2015. Strain distribution in the proximal Human femur during in vitro simulated sideways fall. $\mathrm{J}$ Biomechanics 48(10), 2130-2143. 


\section{APPENDIX I. \\ STRAIN GAUGE MOUNTING INSTRUCTIONS}

-For gauge placement on Lap Bar, steps 1-13 were used. An additional dummy gauge was placed on a neutral $80 / 20$ bar to complete the half bridge.

-For gauge placement on the sawbone and cadaver bones, step 1 was skipped. An additional dummy gauge was place on a neutral sawbone to complete the half bridge.

\section{Protocol:}

1. Degrease metal with CSM-1

2. Use "Conditioner A" acidic surface cleaner, use sandpaper to remove polish and abrase surface

3. Wipe with cloth

4. Clean with $70 \%$ isopropyl alcohol and gauze

5. Wipe again with Conditioner A and gauze

6. Use "M. Prep Neutralizer" and gauze and wipe dry

7. Use forceps to align strain gauge and place on material

8. Place extra nodes below gauge

9. Cover with cellophane tape, press and pull back on tape slowly and lift gauge and nodes off surface

10. Place small amount of Loctite liquid on back of gauge and node

11. Return tape back into position making sure gauges are in place on surface, apply pressure on gauge and node for 5 minutes

12. Remove cellophane tape, gauge and node should be adhered to surface

13. Repeat as necessary 


\title{
VIII. APPENDIX II
}

\section{ANTHROPOMORPHIC DATA (Winter, 2005)}

\author{
Body Segment Masses in kilograms
}

\begin{tabular}{lcrrr|rrr} 
& Body & \multicolumn{3}{c}{ Male } & \multicolumn{3}{c}{ Female } \\
Name & Segment & 5 th\% & 50 th\% & 95 th\% & 5 th\% & 50 th\% & 95 th\% \\
\hline Lower torso (pelvis) & 1 & 8.24 & 10.00 & 11.99 & 8.27 & 10.00 & 12.11 \\
Middle torso (lumbar) & 2 & 9.01 & 10.95 & 13.13 & 5.45 & 6.59 & 7.98 \\
Upper torso (chest) & 3 & 15.30 & 18.58 & 22.28 & 7.69 & 9.30 & 11.25 \\
Upper arm & 4,9 & 1.84 & 2.23 & 2.67 & 1.41 & 1.71 & 2.07 \\
Lower arm & 5,10 & 1.14 & 1.39 & 1.66 & 0.84 & 1.02 & 1.24 \\
Hand & 6,11 & 0.43 & 0.52 & 0.63 & 0.34 & 0.42 & 0.50 \\
Neck & 7 & 1.48 & 1.80 & 2.16 & 1.20 & 1.45 & 1.76 \\
Head & 8 & 4.07 & 4.95 & 5.93 & 3.31 & 4.01 & 4.85 \\
Upper leg & 12,15 & 6.96 & 8.45 & 10.13 & 6.22 & 7.53 & 9.11 \\
Lower leg & 13,16 & 2.84 & 3.45 & 4.14 & 2.24 & 2.71 & 3.28 \\
Foot & 14,17 & 0.85 & 1.03 & 1.23 & 0.71 & 0.86 & 1.04 \\
\hline Total & & 66.22 & 80.42 & 96.41 & 49.44 & 59.85 & 72.43
\end{tabular}




\section{VITA}

Alyssa Osbourne is originally from Cincinnati, Ohio and now has become a resident of Kentucky after attending the University of Louisville's J.B. Speed School of Engineering and receiving her Bachelors of Science in Bioengineering in 2015. Alyssa initially utilized rock climbing as an exercise therapy to overcome her own struggles with a rare genetic connective tissue disorder that affects her joints, including her hips. She then eventually excelled as a competitive rock climber utilizing her hyper-extension to her benefit and as a result discovered a passion for orthopedics, biomechanics, and exercise fitness/rehabilitation. Through all of this she has become personally invested in this type of research. Alyssa is now working as a Product Engineer developing and manufacturing orthopedic medical devices at Vivorte, Inc. After submission of this thesis, Alyssa will receive her Master of Engineering degree in 2017. 